\title{
Özgür Ruh, Ritmik Beden: Bizans Kültür-Sanat Hayatında Dans
}

\section{Free Spirit, Rhythmic Body: Dance in Byzantine Culture \& Art Life}

\author{
Feray Korucu Yağız
}

'Sorumlu yazar/Corresponding author: Feray Korucu Yağız (Araș. Gör. Dr.),

Istanbul Medeniyet Üniversitesi, Edebiyat Fakültesi, Sanat Tarihi Bölümü, Bizans Sanatı Anabilim Dalı, İstanbul, Türkiye

E-posta: feray.korucu@medeniyet.edu.tr ORCID: 0000-0003-2208-7330

Başvuru/Submitted: 21.02.2020

Revizyon Talebi/Revision Requested: 07.04.2020

Son Revizyon/Last Revision Received: 21.04.2020

Kabul/Accepted: 28.04 .2020

Online Yayın/Published Online: 30.06 .2020

Atıf/Citation: Korucu Yagiz, Feray, "Özgür Ruh, Ritmik Beden: Bizans Kültür-Sanat Hayatında Dans". Sanat Tarihi Yıllığı - Journal of Art History 29 (2020), 279-305.

https://doi.org/10.26650/sty.2020.012

\section{Öz}

Dans, çoğu kültürde olduğu gibi Bizans kültür hayatında da önemli bir tema olarak tanımlanmıştır. Konu, sanatçıların elinde can bulup imparatorluğun gayri meşru mührü haline gelen sanat yapıtlarında çokça işlenmiştir. Nitelik ve işlevsel olarak farklı gruplar yaratan eserler üzerinde yer alan tasvirler, eğlence ve neşenin imparatorluğun kültür hayatındaki yeriyle alakalı bilgilere ulaşılmasına aracılık etmiştir. Görsel olarak birtakım veriler sunan tasvirler, bahsedilen tüm bu yönleriyle adeta dile gelen bir dönem sözcüsü kimliğiyle tanınır hale gelmiştir. Bu çalışmada; yeni dini benimseyen, benimsediği din doğrultusunda hayatını düzenleyen Bizanslıların dansı nasıl algıladıkları ve tanımladıkları; bu eylemler dizisini bir şov algısı içerisinde nerede ve hangi aralıklarla tatbik ettikleri; bu tatbiklerde biçim, içerik ve yöntem olarak neleri takip ettikleri; dinin yarattığı kısmî baskıyı dansla nası öteledikleri; genellikle kadına ait görsel bir ifade yöntemi olarak kabul edilen dansın icra edicileri hakkındaki algıları; özgürleşen bedenin kavuştuğu rahatlığı dini ve özel yaşam içerisine dâhil edip edemedikleri ve tüm bu unsurları bir bütünlük göstererek sanat sahasında nasıl işledikleri, konuyla ilgili görseller eşliğinde anlatılmaya çalışılacaktır.

Anahtar kelimeler: Bizans, Kültür tarihi, Sosyal yaşam, Din, Dans

\section{ABSTRACT}

Dance has been defined as a significant theme in Byzantine cultural life as in many other cultures. This was mostly subjected in works of art created by artists which then became an illegal seal of the empire. Descriptions, on works creating different groups in terms of quality and function, mediated to achieve information about the place of entertainment and joy in the cultural life of the empire. The descriptions, providing some data in visual respects, have become known through the identity of a spokesman from the period talking about all these aspects. In this study, it was tried to discuss with the visuals how Byzantines, who embraced a new religion and organised their life in line with this religion, perceived and described the dance; where and at what intervals they performed this sequence of actions in a show perception; what they followed in these performances as style, content, and method; how they postponed the partial pressure caused by religion through dance; how the persons performing the dance 
were generally accepted as a visual expression belonging to woman; whether they could integrate the comfort achieved by a free body into religious and private life and how they subjected all these elements in the artistic field by showing unity.

Keywords: Byzantine, Cultural history, Social life, Religion, Dance 


\section{Giriș}

Sahip olduğu evrensel nitelikleriyle sınırsız bir zamana hitap eden ${ }^{1}$ ve insan yaşamındaki en eski sosyal olaylardan biri olan dans, bu seyir çizgisindeki olguların en önemlilerinden biri olarak nitelenmiştir. ${ }^{2}$

İnanç sistemlerinde, sisteme hizmet eden bir pratik olarak tatbik edilen, ${ }^{3}$ tanrı ve tanrıçalara ulaşmada başat iletişim kanalı olduğu konusunda hemfikir olunan, ${ }^{4}$ hedefe yönelik süreçte var olan ritimle senkronize hareket eden bedenin bir çeşit transa geçme halini ifade eden dans hakkında Bizans dönemi kaynakları yeteri kadar bilgi ortaya koymamıştır. ${ }^{5}$ Buna rağmen son dönemdeki araştırmalarla elde edilen bulguların önceki veri tabanlarıyla bir bütün oluşturacak şekilde kullanılması, alan içerisinde belli bir veri zenginliği yaratmıştır.

Bizans dönemi dans kültürüyle alakalı birincil veri tabanını, olay örgüsünün romantizmle içselleştirildiği döneme ait edebi metinler, epigramlar, dönemin önde gelen aydınları tarafından ortaya konulan eserler, ${ }^{6}$ antik dönemde önemli bir sanat kolu olarak ün kazanan tiyatro ${ }^{7}$ ve buradan ilerlenerek yapılan derin araştırmalar oluşturmuştur. Tarih ve edebiyat başta olmak üzere farklı disiplinlerden yararlanılarak elde edilen bu veriler, geçmiş ve güncel dönem uygulamalarının takip edilebilmesine olanak sağlamıştır. Bizans dönemi dans kültürüyle ilgili tatmin edici açıklamalar yapılmasını olanaklı kılan ve bu anlamda alan içerisinde faaliyet gösteren araştırmacılar için ehemmiyet arz eden ikinci önemli veri tabanını ise görsel kaynaklar oluşturmuştur. Döneme ait anıtsal yapılardaki kompozisyonlar (fresk ve mozaikler), küçük el sanatları (el yazmaları, dokuma, değerli veya yarı değerli madenden yapılmış takılar, günlük

1 ..."Dans adı verilen sanatın evrenselliğini düşünün. O; fikirleri keskinleştirir, bedeni çalıştırır, izleyene zevk verir, geçmiş günleri ögretir. Göz, kulak, flüt, zil ve dansın zarif büyüsünde kalırken geçmişi öğrenir...” Ayrıntılı bilgi için bkz. Lucian (1905), "Of Pantomimes” In the Works of Lucian of Samosata, Trans. by. FOWLER, H. W.-FOWLER, F G., Clarendon Press, UK., 1905, s. 258; http://lucianofsamosata.info/wiki/doku. php?id=home:texts_and_library:dialogues:of-pantomime (13.12.2019); Felix, Hoerburger, "Once Again: On the Concept of Folk Dance", Journal of The International Folk Music Council, Vol. 20, USA, 1968, s. 30.

2 Gerardus, Van Der Leeuw, Sacred and Profane Beauty: The Holy in Art, New York, 1963, s. 74.

3 Dansın dini alanda bir tapınım aracı olarak icra edildiğine dair ayrıntılı bilgi elde etmek için bkz. Elli, LohseClaus, Tanz in der Kunst, Zentralantiquariat Leipzig GmbH, Leipzig, Germany, 1964.

4 Anne-Marie (Anjali) Gaston,- Tony, Gaston, "Dance as a Way of Being Religious", The Oxford Handbook of Religion and the Arts, Ed. By. Frank Burch Brown, Oxford University Press, UK., 2014, s. 2.

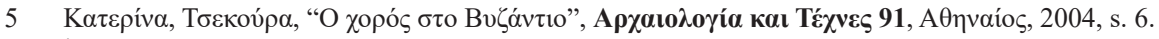

6 İskenderiyeli Klement (Clement of Alexandria) ve Michaelis Psellos eserlerinde dans konusuyla alakalı önemli bilgiler vermişlerdir. Ayrıntılı bilgi için bkz. Clement of Alexandria, The Instructor" (Paedagogus), Fathers of the Second Century: Hermes, Tatian, Athenagoras, Theophilus, and Clement of Alexandria (Entire), Trans. by. William Wilson Vol. II, Christian Literature Publishing Company, New York, 1885; Anthony Robert Littlewood, Michaelis Pselli Oratoria Minora Leipzig, 1985.

7 Yazılı ve nispeten görsel kaynaklar vasıtasıyla elde edilen bilgilerin azlığı, Bizans dönemi dans kültürüyle alakalı çalışma yapmak isteyen araştırmacıları konuyu başka perspektiften incelemeye sevk etmiştir. Bu yönlendirmeden yola çıkan antik dönem yazarları, tiyatronun dans kültürünün oluşumuna kaynaklık ettiğini düşünmüş, bu sebeple kültür hayatı içerisinde önemli bir yeri olan fakat bilgi eksikliği sebebiyle içeriği hakkında detaylı bilgi verilemeyen bu sanatı tiyatro cephesinden yola çıkarak değerlendirmeye çalışmışlardır. Dönem içinde pagan dünyanın ürünü olarak görülen fakat hem kültür hem de sanat hayatında kendince önemli ölçüde yer bulan tiyatronun imparatorluk geleneğindeki yeri hakkında ayrıntılı bilgi elde etmek için bkz. $\Delta \eta \mu \eta ́ \tau \rho \eta \zeta, ~ N \alpha \lambda \pi \alpha ́ v \tau \eta \sigma$,

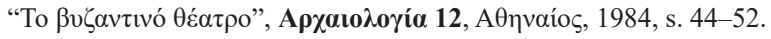


kullanımda ya da ayinsel törenlerde kullanılan kap-kacaklar, litürjik eşyalar vb.) kapsamında ortaya konulan eserler, bu konuda araştırmacılara belli bir perspektif sağlayarak dans eden kişilerin kimler olduğunu, bu kişilerin hangi hareketlerle dans performanslarını zenginleştirdiğini, seçmiş oldukları kostümlerle bu zenginliğe nasıl bir katkıda bulunduklarını, mekân olarak bu gösterileri nerede ve hangi kapsam içerisinde gerçekleştirdiklerini analiz edebilmemize; kısacası dansı biçim, yöntem ve kapsamı bakımından bilimsel anlamda inceleyebilmemize imkân sağlamıştır. Yer ve malzeme fark etmeksizin pek çok yer ve eser üzerinde karşımıza çıkan kompozisyonlar ve bu kompozisyonlardaki dikkat çekici çeşitlilik, dans konusundaki teorik bilgilerin pratiğe nasıl dönüştürüldüğüne ve algılarda nasıl biçimlendiğine ilişkin süreçlerin tahlil edilebilmesine yardımcı olmuştur. ${ }^{8}$

Bizans döneminde, itikadın birincil ilkesi olarak üstün güce ulaşmada inananlarca bir araç olarak kullanılan ve genellikle azizleri/azizeleri ve din şehitlerini anmak için düzenlenen festivallerde ya da kilisede düzenlenen küçük kapsamlı dini törenlerde ${ }^{9}$ tatbik edilen

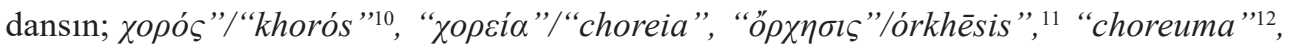
"ó $\chi \eta \dot{\sigma \tau} \rho \alpha ” / “$ orchestra” gibi pek çok farklı kelimeyle tanımlandığı görülmüştür. ${ }^{13}$ Terminolojik açıdan inceleyecek olursak köken olarak Grekçeden gelen -farklı kök ve gövdeden türetilenbu terimlerin hepsi esasında Antik Yunan dans kültüründe de karşımıza çıkmıştır. Bizans'ın kendinden önce var olan birikimi bir miras olarak kabul etmesi, başka bir kültürün öz değerlerinin kendi kültür hayatı içerisine dâhil olmasını olanaklı hale getirmiş bu da terminolojik anlamda saha içinde pek çok farklı kelimeyle karşılaşılmasını sağlamıştır.

Dönem içinde terminolojik olarak pek çok farklı terimle tanımlanan, bazen kutsal kabul

8 Tanım ve açıklamada önemli bir veri tabanı olarak kullanılan görsel kaynaklar, dans konusuyla alakalı bilgi anlamında belli bir temel oluşturmaya imkân sağlasa da, araştırmacılara sınırları geniş tanımlamalar yapmaları için yeterli olanaklar sunmamıştır. Çünkü dans konusunun öncelikli bir anlatım biçimi olarak eserlerde öne çıkıp işlenmesi, dönem sanatçıları tarafından çok tercih edilmemiştir. İnançta kusursuz olmak isteyen sanatçılar, benimsedikleri din kapsamında kötü bir algıyla karşılanan dansı, kendi düşünce ve marifetleriyle görselleştirmekten, bizzat bunun yaratımını gerçekleştiren kişi olmaktan imtina etmiştir. Açıklamaya çalıştığımız bu durum, doğrudan görsel anlamda halkın yaşayış biçiminin ve bu biçim içerisinde oluşturulmuş özgün formun bir ifadesi olan dansın tüm detaylarıyla anlatıldığı kaynaklara ulaşılmasını olumsuz etkilemiştir. Dansın yapılış amacı, içeriği, gelişimi ve türleri gibi pek çok önemli unsurun detaylarıyla sunulmasında zorluk çekilmiş, bu durum özellikle terminoloji konusunda eksikliklerin giderilmesinde sıkıntılar yaşanmasına sebebiyet vermiştir.

9 Peter Robert Lamont Brown, "Enjoying the Saints in Late Antiquity”, Early Medieval Europe Journal, Vol. 9, USA., 2000, s. 1-24.

10 Kelime; Antik Yunan kültüründe var olan ve “chorus” olarak adlandırılan, içinde şarkıların ve dansın birlikte hareket ettiği trajedi türünün de tanımlanmasında kullanılmıştır. Ayrıntılı bilgi için bkz. Laura, Vaughan, Suburban Urbanities: Suburbs and the Life of the High Street, UCL Press, London, 2015, s. 203; Ley, Graham The Theatricality of Greek Tragedy: Playing Space and Chorus, University of Chicago Press, USA., 2010, s. 114.

11 James, Elizabeth, Women, Men and Eunuchs: Gender in Byzantium, Routledge, London, 2013, s. 125.

12 Moran, Neil K., Singers in Late Byzantine and Slavonic Painting, Brill Press, Leiden-Boston, $1986,43$.

13 Kullanımlarıyla erken dönem örnekleri ya da bu dönemde verilen kaynaklar için belli bir pozisyon belirleyen bu tanımların, modern dönem araştırmaları içinde yer almaması, bu anlamda kabul edilebilir bir terminoloji yaratamamış olması, konu hakkında geçmiş ve gelecek arasında kurulması planlanan bağda noksanlıklar

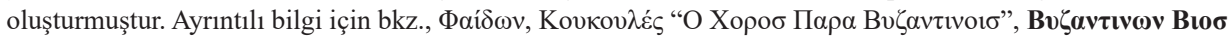

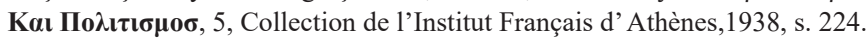


edilen kişilerin mucizelerle dolu hayat hikâyelerinde işlenen ve bu kullanımıyla bir ibadet unsuru olarak görüldüğü anlaşılan ancak bazen de sembolik anlamını kaybederek sözcüğün ilk ve temel anlamı doğrultusunda bedensel bir eyleme terim olan dans, iyi/olumlu ya da kötü/ olumsuz olmak üzere iki anlam kapsamında değerlendirilmiştir. Bu iki farklı perspektif üzerinden ele alınan dans olgusu, görsel eserler üzerinde yer alan tasvirlerin alt ve üst değerlerle olan ilişkisinin çözümlenmesini, kısacası bu alanla ilgili görsel kompozisyonların içerik türlerinin tek tek ele alınarak incelenmesini gerekli kılmıştır. Dansın bir ibadet unsuru olduğu anlayışıyla yapılan inceleme ve irdelemeler ise bu içerik türlerini, üç başlık altında incelememizi sağlamıştır. Bizans dönemi tasvir sanatında dansın anlamsal ve biçimsel yapısının çözümlenmesinde dikkate alınması gereken ilk içerik türünü; pagan inanışların etkisiyle biçimlenen kompozisyon oluşumları ve bir kültür birikimi olarak kabul edilen mitolojik hikâye biçimlerinin yaratımı (iyi/olumlu ya da kötü/olumsuz' a yönlendirme yapan) oluşturmuştur. ${ }^{14}$ Tek tanrı inancını kabul edip hayatını buna göre düzenleyen Hıristiyanların, geçmişten gelen mitolojik birikime sadık kalarak inanç konusunda bu anlatımların etkisi altında kalmaları, ${ }^{15}$ Geç Antik Çağ'ın sonundan Erken Bizans Dönemi’nin sonuna kadar geçen zaman diliminde duygu dünyası için bir yansıma alanı oluşturan sanat sahasında pek çok farklı konu ve kompozisyonla karşılaşılmasına neden olmuştur.

Geç Antik-Erken Bizans Dönemi'nde, dansın pagan inançların ${ }^{16}$ etkileriyle biçimlendirildiğini ${ }^{17}$ kanıtlayan en güzel örneklerden biri Dionysos kültüyle ${ }^{18}$ ilişkili olarak gelişen, Satyr ve Menad'ın ${ }^{19}$ dansının tasvir edildiği gümüş tabaktır (F. 1.). Kahramanların büyük bir estetik

14 Naerebout, Gerard F., Attractive Performances: Ancient Greek Dance : Three Preliminary Studies, J.C. Gieben, Amsterdam, 1997, s. 7.

15 George, Lundskow, The Sociology of Religion: A Substantive and Transdisciplinary Approach, Pine Forge Press, UK., 2008, s. 83-84.

16 Thomas, Steppan, “Tanzdarstellungen der mittel- und spätbyzantinischen Kunst”, Cahiers Archéologiques 45, Paris, 1997, s. 141-142.

17 Antik Yunan'da tanrıların dansların sahibi olduğuna; dansın üstün güçlerle bağlantı kurmada önemli bir iletişim kanalı olarak vazife gördüğüne inanılmıştır. Apollon ve Dionysos'a olan inanç, dansı biçimlendirmiş; yaratılan bu zenginlikte Artemis, Aphrodite, Demeter, Persephone gibi pratikle ilişkili olduğuna inanılan tanrıçaların etkileri göz önünde bulundurulmuştur. İnanç ve dans arasında gerçekleştirilen bu ilişkilendirme, sanat sahasında da yer bulmuştur. Dionysos'un etrafında dans eden Menad ve Satyrlerin, Artemis'le dans eden su perilerinin (nymph), Apollo'nun etrafinda dans eden ilham perilerinin (muse) konu olarak sanat eserleri üzerinde çokça işlenmesi, tasvirlerin içeriklerinin teferruatlarına vakıf olunmasını sağlamıştır. Ayrıntılı bilgi için bkz. Jennifer, Larson, "Handmaidens of Artemis?", The Classical Journal, Vol. 92, No. 3, Pub. by. The Classical Association of the Middle West and South, Inc. (CAMWS), USA., 1997, s. 249; Fritz, Graf, Apollo, Routledge, UK., 2008, s. 33; Walter, Burkert, Greek Religion, Harvard University Press, USA., 1985, s. 173.

18 Dionysos'u; şarabın, kendinden geçme halinin ve eğlencenin sembolü olarak tanımlamak mümkündür. Antik dönemde sıra dışı bir formun imgesi olan bu tanrıya karşı insanların, besledikleri inanç kapsamında çeşitli ritüeller düzenledikleri görülmüştür. Düzenlenen ritüellerde bir ifade kanalı oluşturan danslar ön plana çıkmış, ruh ve bedenin büyük bir ahenk oluşturarak yarattığı bu görsel ifade biçimlendirmesinde içgüdüsel anlamda baskın olan istek-arzu, şehvet ve bu duyguların esaretinde gerçekleşen kendinden geçme halinin sembolik ifadesi yaratılmaya çalışılmıştır. Ayrıntılı bilgi için bkz. Plutarch, Plutarch's Morals, Vol. 4, Ed. by. William W Goodwin, Little, Brown and Company, Boston, 1874, S. 487.

19 Menad, Silen ve Satyrleri; istek, arzu ve orgazmik hisler gibi insanın doğasında var olan duygu ve düşünceleri temsil eden mitolojik yaratımlar olarak tanımlamak mümkündür. Bunlar sanatta en çok Dionysos kültü kapsamında 
incelikle tasvir edildiği kompozisyon, kabartma tekniği kullanılarak eser yüzeyine işlenmiştir. Eserde; sol tarafta, sol kolu havada, hareket yönü sağına doğru olan Satyr tasvir edilmiştir. Başı, sol koluna doğru meyilli bir şekilde tasvir edilen Satyr'in bakışları ise sağ tarafta tef çalıp eğlenen Menad'ın üzerindedir. Sağ göğsünü açıkta bırakan, beden hareketlerinin en ince ayrıntılarıyla çözümlenmesini sağlayan tiril tiril elbisesiyle görülen Menad, sağ eliyle bir mızrak tutar şekilde tasvir edilmiştir. Menad'ın sol kolundan sağına doğru uzanan ve başında zarif bir çember oluşturan ince, uzun ve kıvrımları hafifliğine işaret eden muhtemelen elbisesine ait bir aksesuar olan kumaş oldukça dikkat çekicidir. Sahnede, en alt bölümde, karakterlerin ayaklarının altında, bir çift zil ve hemen sol çaprazda Satyr'in ayaklarına yakın bir yerde pan flüt tasvirine yer verilmiştir.

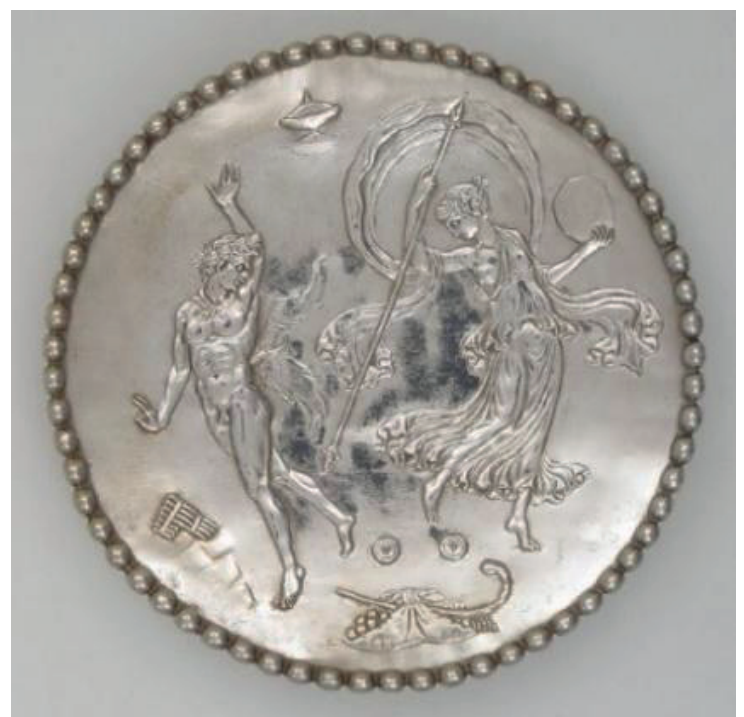

F. 1: Satyr ve Menad'ın Dans1, Gümüş Tabak, Mildenhall Hazinesi, IV. yüzyıl, British Müze (Museum),

Kaynak: https://research.britishmuseum.org/research/collection_online/collection_object details.aspx?objectId $=808634 \&$ page $=1 \&$ partId $=1 \&$ searchText $=$ great $\% 20$ plate $\% 20 \mathrm{of} \% 20$ bacchus $(20.01 .2020)$

Geç Antik-Erken Bizans Dönemi’nde, geçmiş dönem inançlarının etkisi altında gelişen bezeme repertuvarının yeni benimsenen dinin etkisiyle biçimlenen konularla harmanlanması, geliştirilen kompozisyonlarda pek çok farklı türün ortaya çıkarılmasına olanak sağlamıştır. ${ }^{20}$ Dönem içerisinde

gerçekleştirilen ritüellerin tasvir edildiği sahnelerde karşımıza çıkmıştır. Ayrıntılı bilgi için bkz. Helene E., Roberts, Encyclopedia of Comparative Iconography: Themes Depicted in Works of Art, Routledge, UK., 2013, S. 265.

20 IV-VII. yüzyıllar arasına tarihlenen ve erken Hıristiyan döneminde ortaya konulan bu eserler, antik geleneklerin yaşatıldığı bir retrospektif olmamıştır. Yani bir klasisizm yaratma arzusu güdülerek sanatçılar tarafından eserler üzerine işlenmemiştir. Bu durum gelenekler reddedilse de sınırlar içerisinde bu reddin kesin ve kati bir zorunlulukla 
Yunanistan, İstanbul, Filistin, Mısır ve İsrail'den gelmiş olan ${ }^{21}$ tasvir örneklerindeki çeşitlilik, bahsini ettiğimiz bu unsurların tespitinin yapılmasını kolaylaştırmıştır. IV-VII. yüzyıllar arasında Hıristiyan tasvir sanatında paganist etkilerinin varlığını kanıtlayan ya da bu etkilerin benimsenen ve önemsenen değerler olarak kabul edildiğini gösteren Konstantinopolis işi gümüş tabak, bu anlamda önemli bir kanıt kabul edilmiştir (F. 2.). VII. yüzyıla tarihlenen eserde, Tanrı Dionysos'a dans ederek ibadet eden Silen ve Menad'ın² etkileyici görüntüsü, yüzey üzerine kabartma tekniği kullanılarak işlenmiştir. Eserde dengeli bir kompozisyon içerisinde yer alan karakterlerden Menad sol tarafta, elinde bir enstrüman tutar şekliyle tasvir edilmiştir. Sağ tarafta ise bu kültün kışkırtıcı güdülerinin sembolü olan ve sırtında şarap dolu bir deri tulum taşıyarak dans eden Silen tasviri bulunmaktadır.

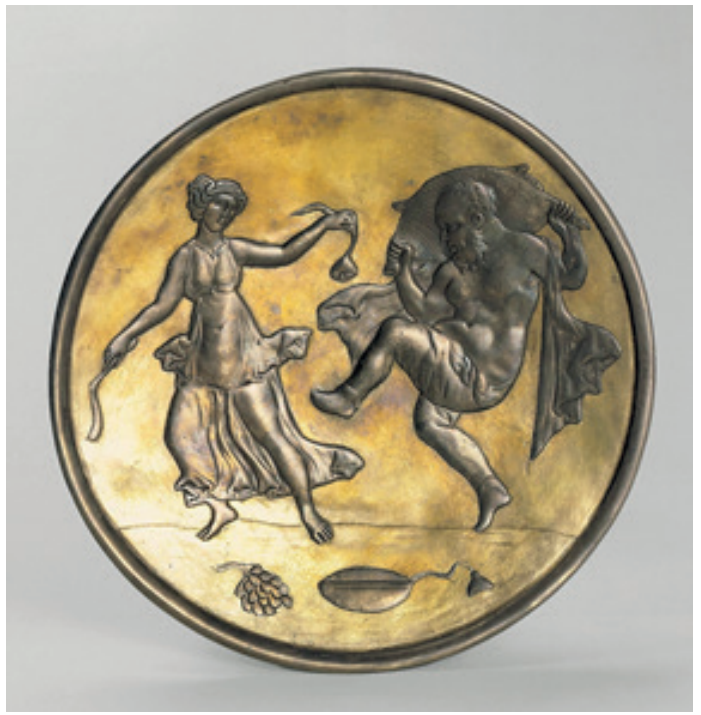

F. 2: Silen ve Menad, Gümüş Tabak, Hermitage Müzesi, VII. yüzyıl, Hermitage Müzesi,

Kaynak: Evans, Helen C.,-RATLIFF, Brandie, Byzantium and Islam Age of Transition, 7th-9th Century, Metropolitan Museum of Art, Yale University Press, New York, 2012, s. 19, fig. 79

Geç Antik-Erken Bizans Dönemi’nde, Doğu’daki eyaletlerden gelen örnekler sadece konu çeşitliliğinin kavranmasına yardımcı olacak detaylar sunmakla kalmamış; bu örneklerden bazıları

yürütülemediğinin ispat niteliğini taşımıştır. Geleneklerin ne yapılırsa yapılsın, birer kültür birikimi olarak adlandırılıp insanların hayalinde yaşadığının göstergesi olarak kabul edilmiştir. Ayrıntılı bilgi için bkz. Ernst, Kitzinger, Byzantine Art in the Making: Main Lines of Stylistic Development in Mediterranean Art, 3rd7th Century, Harvard Univeristy Press, USA., 1977, s. 192. Bizans sanatında paganizm etkisiyle biçimlenen sahneler sadece erken dönemde karşımıza çıkmamıştır. Veroli Kutusu olarak adlandırılan, X. yüzyıla ait eser üzerinde görülen tasvirler, yapılan bu açıklamayı örneklendirmiştir. Ayrıntılı bilgi için bkz. Victoria and Albert Museum; https://collections.vam.ac.uk/item/O70463/veroli-casket-casket-unknown/ (30.11.2019).

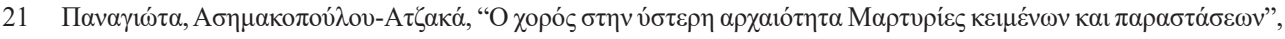

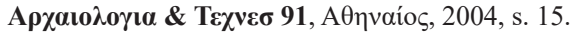

22 Erica Cruikshank, Dodd, - John, Kent, Byzantine Silver Stamps, Washington, 1961, s. 202. 
üzerinde yer alan bezemeler, söz konusu farklı coğrafyalar arasındaki stil/tarz etkileşimlerinin çözümlenmesini de olanaklı hale getirmiştir. Örneğin; VI. (?) yüzyıla tarihlenen, muhtemelen döneminde bir mücevher kutusu olarak kullanılan, kemikten yapılmış bir süs objesi üzerindeki dansçı tasvirleri, bu anlamda kutunun dikkat çekici şekilde İsrail, Yunan ve Suriye etkileriyle biçimlendirilmiş olduğunu göstermektedir (F. 3.).

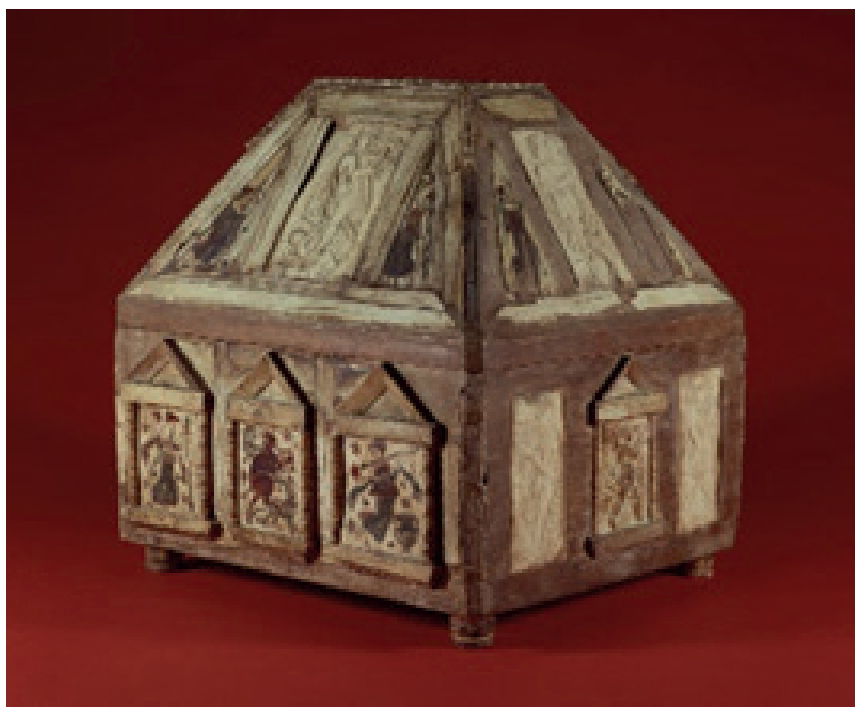

F. 3: Faun ve Dansçılar, Kemik Mücevher Kutusu, VI. (?) yüzyıl, Walters Art Gallery MüzesiBaltimore, Maryland,

Kaynak: https://art.thewalters.org/detail/34927/jewelry-box-with-dancers-and-faun/ $(27.01 .2020)$

Uzun yıllar hâkimiyetini devam ettiren ve bu anlamda güçlü bir devlet imajı çizen Bizans İmparatorluğu'nda, dansın sanat alanındaki kullanımıyla ilgili dikkate alınması gereken ikinci içerik türünü; dansın putperestler tarafindan bir ibadet biçimi olarak kullanıldığ formlar ile bu formların toplum nazarında iyi imajı olmayan insanlar tarafindan ${ }^{23}$ tatbik edilen bir eylemler dizisi olarak görülmesi oluşturmuştur. Tevrat'ta ayrıntılarıyla anlatılan "Baal'in Dansl" "24 ve “Altın Buzağı'ya Tapınanların Dansı" 25 ile İncil'de detaylandırılan "Salome'nin Dansı" "26 ve

23 Ahlaki değerler burada temel kıstastır.

24 Tevrat, I. Krallar, 18:26; “Kendilerine verilen boğayı alıp hazırlayan Baal’ın peygamberleri sabahtan öğlene kadar, "Ey Baal, bize karşılık ver!” diye yalvardılar. Ama ne bir ses vardı, ne de bir karşılık. Yaptıkları sunağın çevresinde zıplayı oynadılar."

25 Tevrat, Mısır'dan Çıkış, 32: 19; "Musa ordugâha yaklaşınca buzağıyı ve oynayan insanları gördü; çok öfkelendi. Elindeki taş levhaları firlatıp dağın eteğinde parçaladı.”

26 İncil, Matta, 14: 6-12; "Hirodes'in doğum günü şenliği sırasında Hirodiya'nın kızı ortaya çıkıp dans etti. Bu, Hirodes 'in öyle hoşuna gitti ki, ant içerek kıza her ne dilerse vereceğini söyledi. Kız, annesinin klşkırtmasıyla, «Bana şimdi, bir tepsi üzerinde Vaftizci Yahya'nın başını ver» dedi. Kral buna çok üzüldüyse de, konuklarının önünde içtiği anttan ötürü bu dileğin yerine getirilmesini buyurdu. Adam gönderip zindanda Yahya'nın başını 
“Ísa'yla Alay Edilmesi” hikâyeleri, bu içerik türü kapsamında incelenmiştir.

Kutsal kitaplarda ibadet anlayışıyla yapılması hoş görülmeyen dans eylemi, toplumsal normlar içinde de kötü' ye/olumsuz' a işaret eden bir olgu olarak tanımlanmış ve onaylanmamıştır. Dince "kabul edilemeyen ifade biçimleri" olarak tanımlanan ve ortak bir kanaatle şiddetle kınanmış bu eylem türü, açıklamaya çalıştığımız anlam kapsamında, Bizans tasvir sanatında “Salome'nin Dansi" ${ }^{27}$ ve "Ísa'yla Alay Edilmesi” konularıyla sanat sahasında yer almıştır.

Bizans Dönemi’nde sanatkârların, İncil'i (Yeni Ahit) temel alarak pek çok farklı konuyu ele aldığ 1 ve üstün bir beceri göstererek bu tematik konuları farklı kullanımlara hizmet eden eserler üzerine işleyebildiği görülmüştür. Her bir sahnenin inananlara farklı yollarla rehberlik edilebileceği fikrinden hareket eden sanatçılar, kutsal kitap referanslarıyla biçimlendirdikleri konuları en çok ibadethanelerin süsleme programlarında kullanmışlardır. Süslemede yalın ve anlamlı bir bütün oluşturan kompozisyonların kullanıldığı mekânlarda, tasvir anlamında ele alınan en nadir örneklerin ise genellikle dans konusu üzerine olduğu görülmüştür.

Bizans tasvir sanatında "Salome’nin Dansl" /"Salome'nin Yedi Tül Dansı"28 ve dansın konu içinde bir öğe olarak yer aldığı "Isa 'yla Alay Edilmesi” konularının ele alındığı sahnelere erken döneme ait ibadet mekânlarının hiçbirinde karşılaşılmamıştır. Bu konuyla alakalı ilk tasvir örnekleri, Orta-Geç Bizans dönemine ait eserler vasıtasıyla tanınır hale gelmiştir. ${ }^{29}$

Dini inanç ve yaşamla alakalı bir ortamda tatbik edilen ve bu bakımdan sanatta ikinci içerik türü içinde incelenmesini gerekli kılan ilk örnek "Salome’nin Dansı"/“Salome’nin Yedi Tül Dansı” hadisesinin işlendiği örneklerle tartışılmıştır.

Vücudunu teşhir ederek dans eden ve danstaki mahareti Vaftizci Yahya’nın başının kesilmesiyle ödüllendirilen Salome, koyu dindar/itaatkârlar tarafından ders çıkarılması gereken bir facianın müsebbibi olarak görülmüş, bu olaydaki sorumluluğu Hıristiyan inancında konunun ayrı parametrelerde incelenmesine neden olmuştur. ${ }^{30}$

kestirdi. Bir tepsi üzerinde getirilen baş genç kıza verildi, kız da bunu annesine götürdü. Yahya'nın ögrencileri gelip cesedi aldılar ve gömdüler. Sonra gidip İsa'ya haber verdiler.” Ayrıca bkz. İncil, Markos, 6: 14-22.

27 Naerebout, Gerard F., a.g.e, 7.

28 Udo, Kultermann, "The "Dance of the Seven Veils". Salome and Erotic Culture Around 1900", Artibus et Historiae, Vol. 27, No. 53, Poland, 2006, s. 187-215.

29 Bizans Dönemi’nde; "Salome 'nin Dansı"/"Salome’nin Yedi Tül Dansı" hadisesiyle alakalı ortaya konulan tasvirler, genellikle mimari yapıların iç dekorasyonunda kullanılacak olan konu biçimlendirmelerinin içinde yer almıştır. Yapılan bu genelleme, Orta Bizans Dönemi’ne tarihlenen bir el yazmasında görülen tasvirle çeşitlense de bize göre hükmünü kaybetmemiştir. Paralel bir görüş için bkz. Steppan, Thomas, "Tanzdarstellungen der mittelund spätbyzantinischen Kunst”, Cahiers Archéologiques 45, Paris, 1997, s. 141-168; 1100 y1lına tarihlenen minyatürün görsel bilgisi için bkz. http://salome.orchesis-portal.org/index.php/before-1800\# (20.01.2020).; İncil ve Tevrat'ta, "Ísa 'yla Alay Edilmesi" meselesinde, dans eden karakterlerin varlığıyla ilgili herhangi bir bilgiye yer verilmemiştir. Ayrıntılı bilgi için bkz. İncil, Matta, 27: 39-43; İ́cil, Matta, 27: 34; İncil, Markos, 15: 23; İncil, Luka; 23: 35-36; Tevrat, Mezmurlar, 22:7-8; Tevrat, Mezmurlar, 69. Sanat sahasında olayın dans eden karakterle tasvir edilişi, XI. yüzyıl sonlarına doğru ortaya konulan eserlerde karşımıza çıkmıştır. Ayrıntılı bilgi için bkz. Kono, Keiko, "Notes on the Dancers in the Mocking of Christ at Staro Nagoričino", Deltion of the Christian Archaeological Society, 27.4, USA, 2006, s. 159-68.

30 Rachael, Langford, Depicting Desire: Gender, Sexuality, and the Family in Nineteenth Century Europe: Literary and Artistic Perspectives, Peter Lang, Oxford, 2005, s. 106. 
Kıyafetinden beden hareketlerine kadar kadınsı özelliklerini müthiş bir etkiyle karşı tarafa aktarabilmeyi başaran bu genç kadının zihinlerde oluşturduğu alg1, ritmik bedenin ruh için yarattığı özgür bir alan, cinsiyetle alakalı toplum algısında var olan sabit biçimin değişimi (kadın bir kimlik olarak bağımsızlık kazanmıştır) ${ }^{31}$ olarak tanımlansa da, sonuçta gerçekleşen ölüm olgusu, bu olumlu algıyı yerle bir etmiş ve gerçekleştirilen eylemin tam anlamıyla şeytani duyguları uyaran bir biçim olarak tanımlanmasına sebebiyet vermiştir. ${ }^{32}$ Temel ve sembolik anlamlarıyla incelendiğinde, farklı yorumların üretilebildiği "Salome'nin Dansı" olayının nasıl algılandığına yönelik bu özel bakış açısını yansıtan en güzel örnek, San Marco Bazilikası Vaftizhanesi’nde yer alan bir tasvirle karşımıza çıkmıştır (F. 4.). Sahnede; Salome, sol tarafta, alt boşlukta dans eder şekilde tasvir edilmiştir. Uzun, tüm vücut hatlarını gösteren kırmızı renkli bir elbiseyle tasvir edilen Salome, bu tasarımla tüm dikkatleri üzerinde toplamayı başarmış görünmektedir. Gerek rengi gerekse tasarımıyla Salome’ye seksapelite kazandıran kırmızı elbisenin kol ve yırtmaç bölümündeki beyaz tüylü aksesuarlar ise tasvire görsel anlamda kazandırılan etkinin kuvvetini artırmıştır. Sağ bacağı hafif önde gösterilerek dansının kıvraklığg bu duruş pozisyonuyla aktarılmaya çalışılan Salome'nin sağ kolu havada tasvir edilmiştir. Genç kız, havada olan sağ eliyle dansın din ve toplum nazarındaki algısını yıkan sonucuna ima eder şekilde, yani Vaftizci Yahya'nın altın bir tepsi üzerine yerleştirilen kesik başını tutar şekilde tasvir edilmiştir.

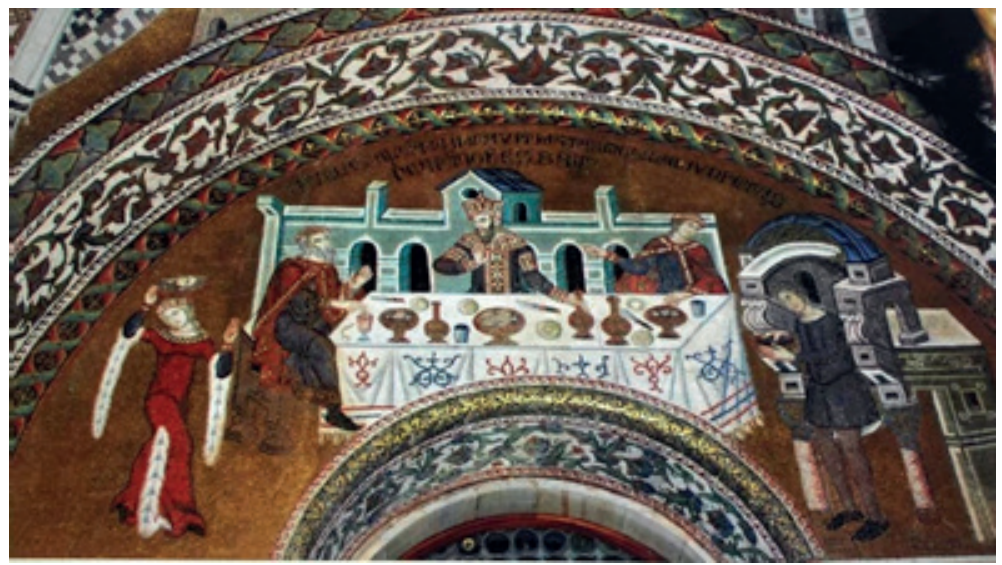

F. 4: Salome'nin Dansı/Salome'nin Yedi Tül Dansı, Duvar Mozaiği,

San Marco Bazilikas1, 1343-1345, Venedik,

Kaynak: D., Grossman, "When the Daughter Came in and Danced:” Revisiting Salome's Dance in Medieval and Early Modern Iconology", Interruptions and Transitions: Essays on the Senses in Medieval and Early Modern Visual Culture, Baert, Barbara, Brill Press, USA, 2019, s. 190, fig. 76

31 Petra, Dierkes-Thrun, Salome's Modernity: Oscar Wilde and the Aesthetics of Transgression, University of Michigan Press, USA, 2014, s. 12.

32 Rosina, Neginsky, Salome: The Image of a Woman Who Never Was, Cambridge Scholars Publishing, USA., 2014, s. 25. 
Dansın ibadet maksadı dışında kullanılışını, dolayısıyla hem sosyal ve kültürel yaşamda hem de sanat sahasında dans üzerine kurulan olumsuz biçimlendirmenin anlamının kavranmasını kolaylaştıracak bir diğer örnek; Aziz Georgij Kilisesi'nin (Staro Nagoričane, Makedonya) kuzey duvarında yer alan bir tasvirde karşımıza çıkmıştır (F. 5.). "Ísa 'yla Alay Edilmesi" olayının konu edildiği kompozisyonda dikkat çeken en önemli hususu, sahnenin orta noktasına yerleştirilen İsa'nın sol ve sağ tarafında dans eden çocuk tasvirleri oluşturmuştur. Kol kısımları uzun kostümleriyle dans eden çocukların, kalabalığın içinde çalgı çalan kişilerle bir bütünlük yaratacak şekilde tasvir edilmesi, ele alınan konuya içeriğinin dışında bir eğlence havasının yansımasını sağlamıştır.

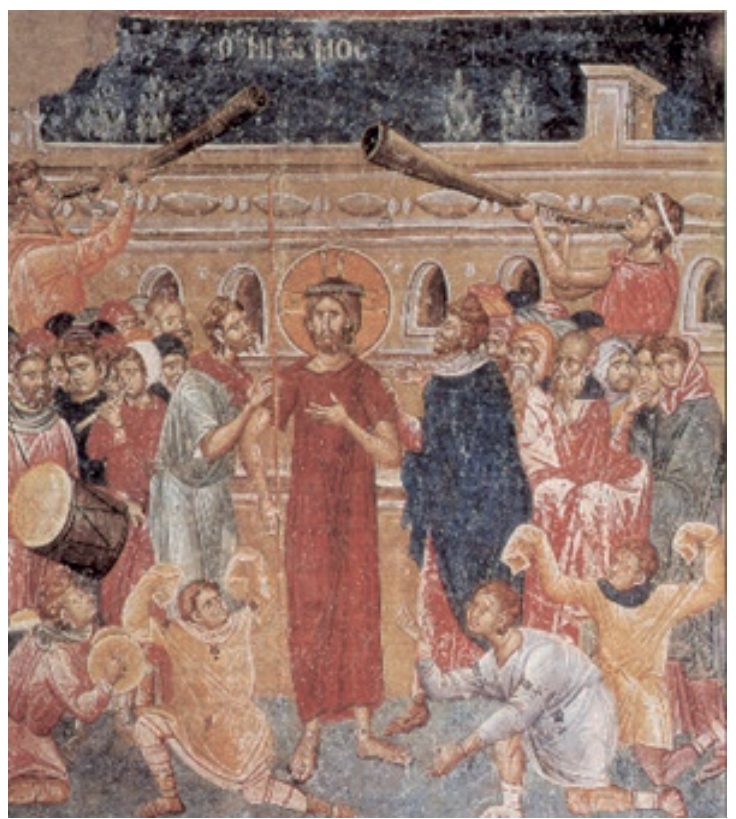

F. 5: İsa’yla Alay Edilmesi, Fresk, Aziz Georgij Kilisesi, XIV. yüzy1l, Staro Nagoričane,

Makedonya,

Kaynak: https://dd5a2c7c-a-62cb3a1a-s-sites.googlegroups.com/site/byzantinedance/ home/page-2/14th-century-ad/P6271B.JPG?attachauth=ANoY7cps_b0LsI_VrrqNtB9N PPi9dpG083sWSGsLKhQV2d7zrM7Otg5almtBiEOV-wMG8h0z0kxCTT0VQAbBWe tljJjvq1JX3SmkqmoLd9Iuf9-K_esyZyLTWoxNWLUiTUV1WTWyzI9in612rlLwnPnGjfn4E3jvvieGiCeuCY1op_m6LgRP9H8sbxoHg3iBQD-HnZGKUdfdBMZ2ZXF0e2i0CEfMK BKdx04pRqNypuKG84E4kBdXT-d2IUF3QRuSR8Z-4-tU678\&attredirects=0 (27.01.2020).

Dönemin sanat eserleri üzerinden hareket edildiğinde, dansın Bizans/Hıristiyan sanatındaki yerinin anlamlandırılmasında dikkate alınması gereken üçüncü ve son içerik türünü; Klasik Dönem ve Yahudi kaynaklarının referans olduğu teolojik-alegorik kullanımda işlerlik kazanan biçimlerin oluşturduğu görülmüştür. İbadet niyetiyle geliştirilen ve genellikle dini anlamda önemli kabul edilen kişilerin yapmış olduğu bu danslar, toplum bilincinde iyi'ye/olumlu'ya sevk 
eden hareketler dizisi olarak tanınır hale gelmiştir. "Davut Peygamber'in Dansı", "Miryam'ın Dansl” ile cennet ve mistik algıyı işaret eden "Dairesel Danslar” bu içerik türünde en çok işlenen konular olmuştur. ${ }^{33}$

Tevrat (Eski Ahit) hükümleri incelendiğinde, dansın genellikle sonu mutluluk ve başarıyla tamamlanan olayların içerisinde yer aldığı görülmüştür. Bu anlamda Tevrat’ta ayrıntılı olarak anlatılan dansla ilgili bazı olayların analizi yapılmış, bu meselelerde dansın kazanılan zaferler sonrasında hissedilen coşkunun yaşam içerisinde somut olarak ifade edilme biçimi olarak algılandığı kanısına varılmıştır. Zira Davut Peygamber ve Miryam tarafından güzel olayların akabinde yapılan dans biçimleri, dansı bu anlam ve kapsamda değerlendirmemizi olanaklı hale getirmiştir. Minnet duygusunun “inanan”dan “inanılan” ” ulaştırılmasında sağlam bir iletişim aracı olarak işlev gördüğüne inanılan bu formun, İncil'de de aynı algı doğrultusunda söz konusu edildiği tespit edilmiştir.

Kutsal kitaplarda geçen hükümlerin referans alınması, dansta sadece amaç ve yöntem anlamında belli bir gelişim ve dönüşüm yaşandığını gösteren bir durum değildir; aynı zamanda bu hükümler, anlamsal ve biçimsel olarak değişen ve başka bir mana kazanan dansın, sanat cephesine yansıyış şeklinin belirlenmesini de kolaylaştırmıştır. Hissedilen olumlu duyguların (şükür/minnet) Tanrı'ya iletilmesinde bir araç olarak kullanılan, bu şekliyle aslında yine bir ibadetin parçası olarak icra edilen dansın, ${ }^{34}$ içinde bulunduğu hikâyelere göre şekil alması ve tasvir edilerek sanat eserleri üzerine aktarılması, Orta ve Geç Dönem Bizans sanatında dansın anlam ve anlatımına özgün nitelikler kazandırıldığını göstermektedir. Antik geleneklerin pagan nitelikli zengin biçimlendirmeleri tam anlamıyla terk edilmiş; dans olgusu, kabul edilen yeni dinin yönlendirdiği değerler doğrultusunda algılanmaya ve bu algıları esas alan biçimlerle sanat eserleri üzerinde canlandırılmaya çalışılmıştır.

Bizans tasvir sanatında dansın teolojik-alegorik kullanımını esas alan bir biçimle örneklendiği en güzel temsillerden biri; “Davut Peygamber 'in Dansı”nı konu alan kompozisyonlardır. Dans genellikle askeri bir zafer sonrasında, muzaffer olan şahsın takdir edildiği olayların sanatsal anlatımında yer almıştır. Bu durumun en güzel temsili, $\mathrm{X}$. yüzyıla tarihlenen bir minyatürde görülmektedir (F. 6.). Söz konusu minyatürde; Filistin'den zafer kazanarak dönen ve Kudüs'e giriş yapan Davut Peygamber'in danslarla karşılanışı tasvir edilmiştir. Sevinç ve coşkuyla dolan bir ruhun hissettiği rahatlık, sahnenin sol tarafında kıvrak dans eden, yaptığı dansın görselliği uçuş uçuş elbisesiyle daha etkin hale getirilen bir kadın figürüyle aktarılmaya çalış1lmıştır. ${ }^{35}$

Bizans tasvir sanatında; zafer kazanan ve bu özelliğiyle güç ve ihtişam sahibi bir karakter olarak kabul edilen Davut Peygamber, elde ettiği başarıdan dolayı neşe ve mutluluğunu ifade etme anlamında Tanrı'ya bizzat dans ederek şükür ve minnet duygularını sunan kişi

33 Gerard F. Naerebout, a.g.e., 7.

34 Tevrat, Mezmurlar, 30:12; “Öyle ki, gönlüm seni ilahilerle övsün, susmasın! Ya RAB Tanrım, sana sürekli şükredeceğim."

35 Olenka, Z. Pevny, The Glory of Byzantium; Perceptions of Byzantium and Its Neighbors; Metropolitan Museum of Art, New York, 2000, s. 90. 
olarak tasvir edilmiştir. XII. yüzyıla ait bir el yazmasında bulunan bir tasvir, bu durumu örneklemiştir (F. 7.). Eserde, üzerinde kol kısımları elleri kapatacak kadar uzun bir kıyafet olan Davut Peygamber, bir kağnıyla Kudüs'e getirilen Ahit Sandığı'nın önünde dans eder biçimde tasvir edilmiştir. ${ }^{36}$

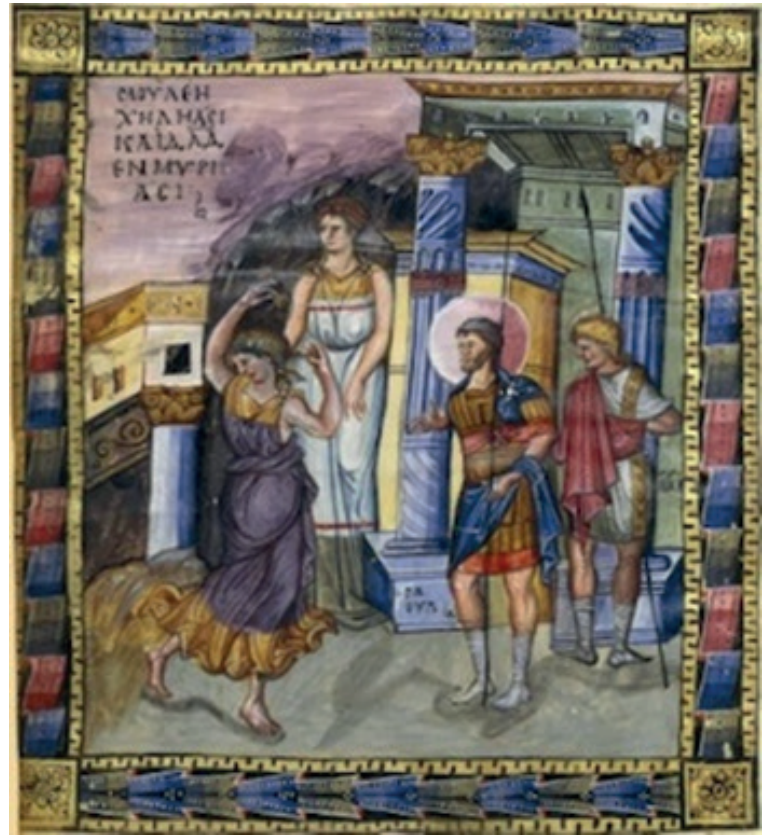

F. 6: İsrail Kadınlarının Filistin'den Zaferle Dönen ve Kudüs'e Giriş Yapan Davut Peygamber'i Dans Ederek Karşılaması, El Yazmas1, X. yüzyı1,

Kaynak: Paris, Bibliothèque Nationale, MS. gr. 139, fol. 5 


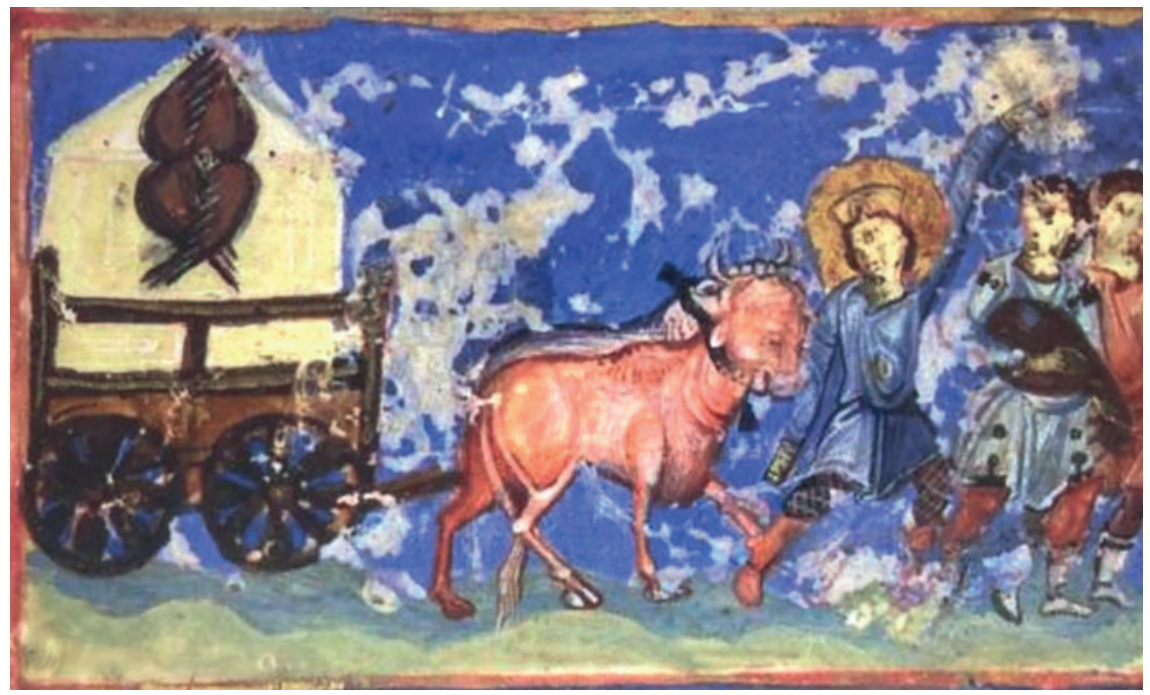

F. 7: Ahit Sandığının Önünde Davut Peygamber'in Dans Etmesi, El Yazması, XII. yüzyıl,

Kaynak: Biblioteca ApostolicaVaticana, Vat. gr. 333, fol. 46 r

Bir ibadet biçimi olarak tatbik edilen ve bu yönüyle Hıristiyan tasvir sanatında üçüncü içerik kapsamında işlenen dans temalı bir diğer kompozisyon da "Miryam 'ın Dansı" 'dır. ${ }^{37}$ Şükür ve minnet duygularının ifade edilişini simgeleyen bu hikâye, dönemin yaratıcı kimliğini gösteren tasvir sanatında, en temel ve en özel kompozisyon olarak işlenmiştir; bu durum tasvir sanatı bağlamında vurgulanması gereken bir ayrıntıdır. Çünkü olumsuz olduğu düşünülen, eleştirilen; ötekileştirilen ve ötelenen, kadın dansının (Salome'nin dansıyla bu böyle olmuştur) dinsel ikonalara saldırıldığı ikonoklast dönemde dini alanda ayrı bir anlam ve işlev ifade eden el yazmalarında “Miryam'ın Dansı" temasıyla işlenir hale gelmesi, gerçekten dikkat çekmiştir. ${ }^{38}$

Kadın ve dans konusuyla ilgili olumsuz algıya rağmen toplum ve sanatçılar nezdinde farklı bir imajı olan Miryam'ın büyük bir sempatiyle karşılanmasında elbette ki birden fazla unsur etken rol oynamıştır. Bu etkenlerden en başta geleninin Yahudi inancının temelini oluşturan Tevrat'taki anlatımlar olduğu bilinmektedir. Kutsal kitap; Miryam'1 bir peygamber, bir peygamber kardeşi olarak tanıtmış; böylece Miryam'ın dansçı kimliği, bu sıfatlar altında değerlendirilen bir özellik haline gelmiştir. Kardeşi Musa'dan önce peygamberlik göreviyle şereflendirilen Miryam'ın bu sıfatıyla yapmış olduğu dans, dini anlamda kurtuluşa vesile olan bir araç olarak algılanmıştır. Sonuç olarak; Davut Peygamber'in dansında olduğu gibi, Miryam'ın dansı da zafer

37 Tevrat, Mısır'dan Çı1kış, 15: 20-21; “Harun'un ablası Miryam tefini eline aldı, bütün kadınlar teflerle, oynayarak onu izlediler. Miryam onlara şu ezgiyi söyledi: "Ezgiler sunun RABB'e, çünkü yüceldikçe yüceldi, atlarl, atlıları denize döktü."

38 Olenka, Z. Pevny, a.g.e., 90. 
sonrasında iyi'ye/olumlu'ya sevk eden hareketler dizisi olarak değerlendirilmiştir. ${ }^{39}$ Miryam'ın bir kurtuluş simgesi olarak icra ettiği, aynı zamanda inananlar tarafından Miryam'ın şükür ve minnet hislerini sunma biçimi olarak kabul edildiği dansin ${ }^{40}$ sanatsal kalitesi en yüksek örneklerinden biri, ikonoklast dönemindeki bir eser üzerinde karşımıza çıkmıştır (F. 8.). Karakterlerin yatay olarak üç ayrı kesitte yerleştirildiği kompozisyonda, en solda Musa Peygamber'in tasvirine yer verilmiştir. Elinde uzun bir asa /sopa tutan Musa Peygamber'in hemen önünde, sahnenin orta noktasında, İsrail halkından bazı kişiler tasvir edilmiştir. Alkış tutarak belli bir ritim oluşturan bu kişilerin, sahnenin en sağında, Kızıl Deniz'in geçilmesi sebebiyle zafer dansı yapan Miryam'a eşlik ettiği görülmüştür. Uzun, kıvırcık saçları her iki omzunun üstüne dökülür şekilde tasvir edilen Miryam'ın, iki eli havada zil çalarak yapmış olduğu dans oldukça etkileyicidir. Eserde, karakterin etek ucunda meydana gelen kıvrımlar, dans esnasında yapılan ayak hareketlerinin canlılığını adeta gerçek bir görüntüyle izleyiciye aktarmaktadır. ${ }^{41}$

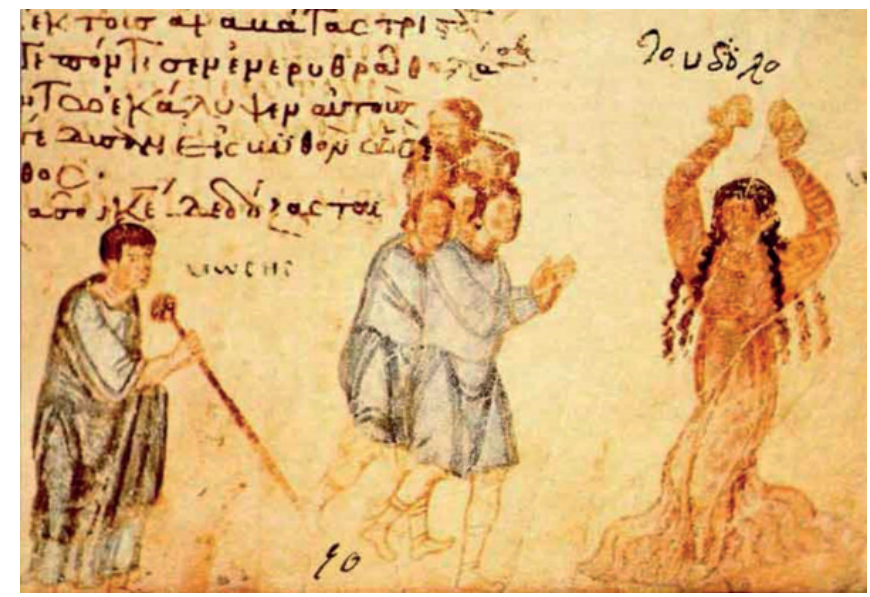

F. 8: Miryam'ın Dans1, El Yazması, IX. yüzy11,

Kaynak: Psalter, Cod. Athos Pantokrator 61, fol. 206 r

Miryam’ın tek başına icra ettiği bu kutsal görünümlü dans formu, daha sonraki dönemlerde

39 Angela M., Yarber, Dance in Scripture: How Biblical Dancers Can Revolutionize Worship Today, Wipf and Stock Publishers, Eugene-Oregon, 2013, s. 13; Nehemia, Polen, "Miriam's Dance: Radical Egalitarianism in Hasidic Thought”, Judaism, Vol. 12, No. 1, Oxford University Press, UK. 1992, s. 1-21.

40 Tanrı'yla kurulacak olan iletişimde, O’na olan bağlılığı ve minneti ifade edeceğine inanılan Miryam'ın dansı bir kurtuluş vesilesi olarak görülmüş, bu nedenle İsrail halkı için kutsal kabul edilmiştir. Ayrıntılı bilgi için bkz. David L., Bartlett, Barbara, Brown Taylor, Feasting on the World Preaching the Revised Common Lectionary, Year A, Volume 2 Lent Through Eastertide, Westminster John Knox Press, USA., 2010, s. 332.

41 Görsel için ayrıca bkz. http://www.hellenicaworld.com/Byzantium/LX/en/DanceOfMiriam2.html (27.01.2020). Miryam'ın Kızıldeniz'in geçilmesi adına yapmış olduğu zafer dansının tasvir edildiği örneklerin sayısını çoğaltmak mümkündür. IX. yüzyıla ait bir diğer örnek hakkında ayrıntılı bilgi elde etmek ayrıca bkz. Chludov-Psalter, Moskau Hist. Museum Cod. 129, fol. 148 v. http://diglib.library.vanderbilt.edu/act-imagelink.pl?RC=55470 (27.01.2020); Homilien des Gregor v. Nazianz, Cod. Parisinus gr. 510, fol. 264 v. https://gallica.bnf.fr/ark:/12148/ btv1b84522082/f542.highres (27.01.2020). 
uygulama açısından bazı farklılıklarla yeniden düzenlenerek eserler üzerine işlenmiştir. İtaat ve ibadeti esas alan bir yaklaşımla icra edilen dansta yepyeni bir forma geçilmiş; birden fazla kişinin katılımının sağlanmasıyla çeşitlenen ve içerik olarak üçüncü başlık altında incelenmesi gereken "Dairesel Danslar" 42 öne çıkmaya başlamıştır. ${ }^{43}$ İbadethaneler ve el yazmaları gibi farklı alanlar üzerine işlenerek cennetin ve barışın sembolize edildiği bu dairesel dans biçimleri, esasında antik dönem geleneklerinin bir devamı olarak gelişme göstermiştir.

"Dairesel Danslar" kategorisinde kadın bedeninin cezbedici etkileri tamamen elimine edilmiş, bu anlamda kadının dans konusundaki yeri ve işleviyle alakalı köklü bir değişim gerçekleştirilmiştir. Eski kıvrak hareketlerin yerine daha sakin hareketlerin hâkim olduğu, dolayısıyla bir ibadet ruhuyla icra edilerek duygu yoğunluğunun artırıldığı "Dairesel Danslar"ın en güzel örneklerinden biri XII. yüzyıla tarihlenen bir el yazmasında karşımıza çıkmıştır (F. 9.). Eserde; Miryam ve 13 kadının birbirlerinin omuzlarından tutarak oluşturduğu dairesel dans, sözü edilen konunun ana kurgusunu oluşturmuştur. Bu sanatsal kompozisyonda, dansa katılım gösteren tüm kadınların bedenen sükûnet ve dinginlik içinde oldukları görülmektedir. Bu huzur ve sükûnet anının tasvir edildiği sahnede, görsel zenginliğin kadınların kıyafetlerinin tasarımıyla elde edilmesi yoluna gidilmiştir. Kol kısımları uzun ve sivri uçlar bırakacak şekilde tasarlanan kostümler, büyük ebatlı şapkalarla kombin edilmiştir. Canlı ve parlak renklerle görsel etkisi kuvvetlendirilen kostümlerin bu şekildeki tasarımları dikkat çekmektedir.

42 Dairesel danslar hakkında ayrıntılı bilgi elde etmek için bkz. Hugh, Nibley, "The Early Christian Prayer Circle", Brigham Young University Studies Quarterly: Vol. 19/1, UK., 1979, s. 1-37.

43 Çoktanrılı dinlerin tapınım ritüelleriyle ilişkili bir gelişim gösteren dairesel dansların bu biçimlendirmenin dışındaki kullanılışına işaret eden örnekler, Hıristiyan tasvir sanatındaki özgün biçimlendirmesini XI. yüzyıldan

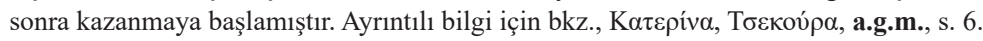




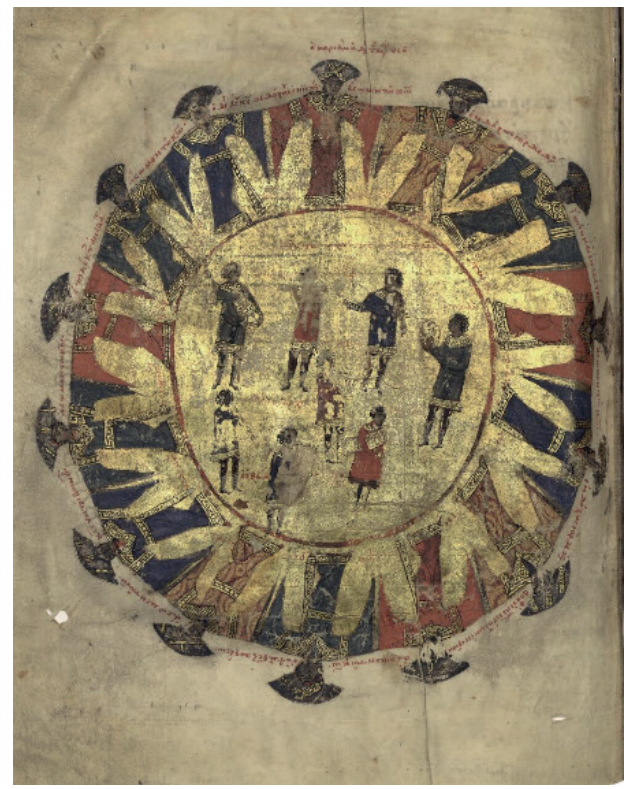

F. 9: İsrailli Kadınların ve Miryam'ın Dansı, El Yazmas1, XI. yüzyıl,

Kaynak: Biblioteca ApostolicaVaticana, Vat. gr. 752, fol. 449 v

Bir tapınım ritüeli olarak ortaya çıkan fakat daha sonra eğlence ve neşeyi de işaret eden bir biçime dönüşen dansın Bizans Dönemi’nde de sadece inanç kapsamında yapılmadığı bilinmektedir. Kimi zaman dinginliğe kavuşmak isteyen ruh için kimi zaman da ruh ve bedenin birlikte hareket etmesine olanak tanıyarak insan için özgür bir alan yaratan dansın, statü, yaş, cinsiyet fark etmeksizin her türden insan tarafından tatbik edilmesi, bunun ispatı niteliğindedir.

Hissedilen duyguların bir çeşit dışavurum biçimi olarak geliştirilen dansın, siyasi yaşamdan sosyal yaşama, inançtan kültür hayatına pek çok sahada aktif olarak kullanılması, bu bedensel pratiğin farklı anlamlar ve işlevlerle donatılmasına imkân sağlamıştır. Bu özelliğiyle dans, ortak bir kültür değerinin yaratılmasında da önemli bir öz değer olarak görev almıştır. Dansın inanç dışında sosyal yaşam için de taşımış olduğu bir anlamı vardır ve dans, bu anlamıyla insana inanca göre nispeten daha rahat bir alan sunmaktadır. Dansın günlük yaşam içindeki icra ediliş şekli, bu nedenle büyük önem taşımıştır.

Antik dönem gelenekleri ve yeni benimsenen dinin etkisiyle hayatlarını düzenleyen Bizanslıların; günlük ya da sosyal yaşam içinde dansı en çok Kalends, ${ }^{44}$ Paskalya, ${ }^{45}$ Rosalia/ Rosaria ${ }^{46}$ Brumalia, ${ }^{47}$ Hamsin Yortusu ${ }^{48}$ gibi pagan dönem ve Hıristiyan gelenekleri kapsamında

44 Roma döneminde, yeni yıl törenleri adına düzenlenen festivallerdir.

45 Hıristiyan toplumlarda, İsa'nın çarmıha gerildikten sonra 3. günde dirilişinin kutlandığı bayramlar kapsamında düzenlenen festivallerdir.

46 Rosalia/ Rosaria (Roussalia) Roma döneminde mayıs ayında kutlanan gül festivalleridir.

47 Roma döneminde, Satürn/Cronus ve Ceres/Demeter ve Bacchus’u onurlandırma maksadıyla düzenlenen festivallerdir.

48 Hamsin Yortusu (Pentecost), Hıristiyan cemaati için önemli bir bayramdır. 
geliştirilen, içerik olarak dinî ve seküler biçimlere hizmet eden festivallerde; imparatorların taç giyme merasimlerinde; askeri sahada elde edilen zaferlerin veya bir şehrin kuruluşu ya da kurtuluşu maksadıyla düzenlenen törenlerde; saray erkânının, devlet adamlarının ya da aristokrat kesimin bireysel olarak düzenledikleri eğlence programlarında; eğlence unsurunun ön plana çıktığı, insanların içki içerek keyif ve zevk alma derecelerini artırdıkları özel amaçlı şölenlerde; doğum günlerinde; düğün ve taverna gibi şenlikli toplantı biçimlerinin gerçekleştirildiği organizasyonlarda tatbik ettiği görülmüştür. ${ }^{49}$

Bizans Dönemi’nde ibadet ya da eğlence amacı güdülerek düzenlenen organizasyonlarda, bu organizasyonların maksadı doğrultusunda değişik koreografilerin uygulandığı dans eylemleri gerçekleştirilmiştir. Adım ve hareketlere göre kurgulanan bu koreografilerde kendine özgü uygulama biçimleri tercih edilmiştir. Bunlardan en önemlisi ve halk tarafından en çok tatbik

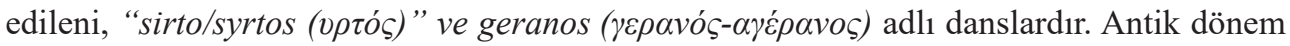
geleneklerinin bir izi ${ }^{50}$ olarak Bizans kültür ve sanat hayatına da intikal eden bu dans biçimlerinde,

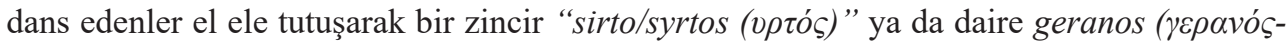

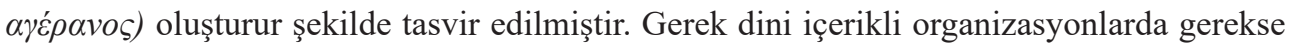
seküler alana hizmet eden ortamlarda bu şekliyle tatbik edilen dans eylemi, Bizans sanat eserleri üzerinde de benzer kompozisyonlarla işlenmiş, bu da söz konusu dans biçimlerinin tüm detaylarıyla tanınır hale gelmesini sağlamıştır (F. 10.). ${ }^{51}$

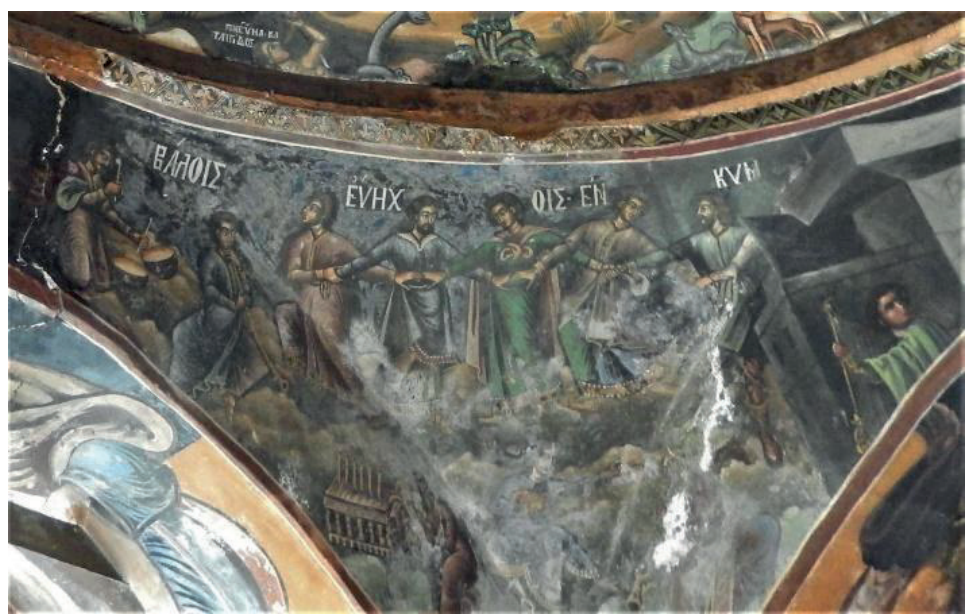

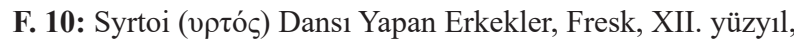

Koutloumousiou Manastır Kilisesi, Athos,

Kaynak: https://athosweblog.com/2017/05/04/1910-koutloumousiou-monastery-part-3/

(30.01.2020)

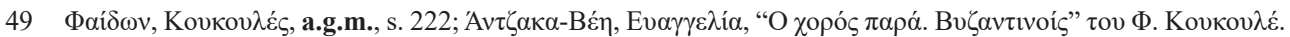

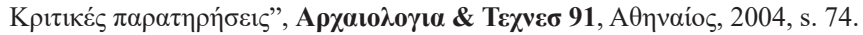

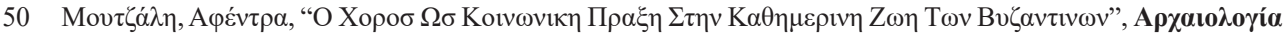

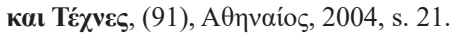

51 Dansın daire biçiminde gerçekleştirilen şekline Miryam’ın dansı örnek verilebilir (Bkz. Resim 9). 
Antik dönem etkileriyle biçimlenen ve kültürel aktarım yoluyla Bizans kültür ve sanat hayatına giren bir diğer dans türü, "cordax" ve "methe” olmuştur. ${ }^{52}$ Genellikle keyfine düşkün, içkiyi zevkin de ötesinde adeta kendinden geçme hali için kullanan erkeklerin rağbet ettiği bu dans türünde, dansı icra eden kişinin şarkılar söylediği, "kithara” adı verilen enstrüman eşliğinde seri ayak hareketleriyle dans ettiği bilgisine erişilmiştir. ${ }^{53}$

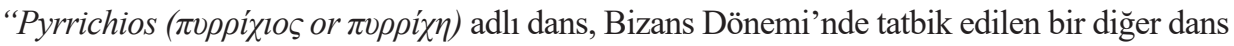
türüdür. Askeri zaferlerin kutlandığı törenlerde uygulanan bu dans, erkekler tarafindan icra edilen bir dans biçimi olarak gelişim göstermiştir. Ulusal bir kimliğin oluşumunda önemli bir kültürel değer olarak işlev gören bu dans biçiminin tasvir sanatında çok fazla örneğiyle karşılaşılmasa da Bizans yaşam kültüründe uygulanmakta olduğunun bilinmesi bile sanat dünyası için önemli bir veridir. ${ }^{54}$

Bizans Dönemi kültür ve sanat hayatına antik dönem biçimlendirmesi olarak giren bir diğer dans türü ise "anastenaria” dır. Hastalıkların iyileştirilmesi maksadından hareket edilerek yapılan ve bir çeşit transa geçme haline işaret eden bu dans biçimi, bir bakıma bir psikoterapi yöntemi olarak kullanılmış; bu amaçla kaygı, hastalık, acı gibi olumsuz duygular ile tezat teşkil edecek şekilde tasvir edilen dans figürlerinin insan üzerinde olumlu etkiler bırakacağ düşünülmüştür. ${ }^{55}$ Bir terapi yöntemi olarak işlev kazanan bu türdeki dansın en önemli özelliği, dansı gerçekleştiren kadınların dans esnasında eyleme liderlik eden azizin üstün güçleriyle buluşacaklarına olan inançlarıdır. Ruhen yaşanan bu transformasyon, toplumun kadın ve dans hakkındaki kısmen olumsuz imajının değişimini sağlamıştır. ${ }^{56}$

İbadet, arınma ve eğlence gibi farklı amaçlarla yapılan pek çok dans türünün görüldüğü tasvirlerden, o dönemde uygulanmakta olduğu anlaşılan bir diğer dans türünün "makellarides” olduğu anlaşılmaktadır. Paskalya Bayramı'ndan hemen sonra Baş Melek Mikhail'in onuruna düzenlenen organizasyonda yapılan bu dans biçimiyle alakalı başka bir bilgiye erişilememiştir. ${ }^{57}$

Bizans kültür hayatında yer alıp sanat eserleri üzerinde işlenen ve böylelikle hakkında detaylı bilgiye eriştiğimiz bir diğer dans türünü, “mantilia/mandilias ( $\mu \alpha v \tau i \lambda \imath \alpha-\mu \alpha v \tau \dot{\lambda} \lambda \imath \alpha)$ )" terimiyle tanımlanan eylemler dizisi oluşturmuştur. Genellikle doğu toplumları tarafından icra edilen bu dansta, kumaş parçaları (ince uzun formlu bu kumaşları şal ve fular olarak tanımlayabiliriz) kostümlerin tamamlayıcısı olarak kullanılmış, bahsi geçen aksesuarların kullanımı bu dans biçimi için belirgin bir özellik yaratmıştır. ${ }^{58}$

52 Johannes, Koder, "Kordax Und Methe: Lasterhaftes Treiben in Byzantinischer Zeit", Zbornik Radova Vizantoloskog Instituta, 50/2, Serbia, 2013, s. 947-958.

53 Nicetas, Choniates, O City of Byzantium: Annals of Niketas Choniatēs, Trans. by. Harry J. Magoulias, Wayne State University Press, Michigan, 1984, s. 64.

54 Paul, Speck, Understanding Byzantium: Studies in Byzantine Historical Sources, Ed. by. Takacs Sarolta, Routledge, USA., 2003, s. 291.

55 Loring M. Danforth, "The Rôle of Dance in the Ritual Therapy of the Anastenaria", Byzantine and Modern Greek Studies, Cambridge University Press, 1979, s. 141.

56 Loring M., Danforth, "Power through Submission in the Anastenaria", Journal of Modern Greek Studies, Vol. 1, No. 1, Johns Hopkins University Press, USA., 1983, s. 203-205.

57 http://www.rebetikoseminar.com/wp-content/uploads/2015/12/praktika_3_2011.pdf (29.01.2020).

58 Stiga, Kalliopi, Kopsalidou, Evangelia, "Music and traditions of Thrace (Greece): A Trans-Cultural Teaching 
Başlı başına bir tür oluşturan "mantilia/mandilias ( $\left.\mu \alpha v \tau i ́ \lambda l \alpha-\mu \alpha v \tau \eta^{\prime} \lambda l \alpha\right)$ ” dansında, dansçılar birbirlerinin el ya da omuzlarından tutuşarak bir bütünlük oluşturmuş; bir daire geranos ( $\gamma \varepsilon \rho \alpha v o ́ \varsigma$ -

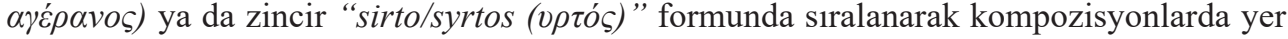
almışlardır. Ardışık sahnelerde ise dansçılar bu formu terk ederek dansta yüz yüze geldikleri şekille tasvir edilmiştir. Duruş pozisyonlarında yapılan bu değişiklik ile dansçıların hem hareket hem de baş aksesuarlarını kullanarak kompozisyonda bir ahenk oluşturmaları sağlanmıştır. Uzun kumaşları tutan eller havaya kaldırılmış, belli bir düzeni takip eden hareketlerle eller sağa ve sola sallanmış; rengârenk kumaşlarla baş üstünde yarım daire biçimli şekiller yaratılmıştır. Ritmik bir uyumla uygulandığı anlaşılan dansın sanatsal temsilleri, yaşanan coşkunun ahenk ve güzelliğini sağlamıştır. Miryam ve etrafındaki kadınların dansının tasvir edildiği XIV. yüzyıla ait bir el yazması, bu anlamda kayda değer bir önem taşımaktadır (F. 11.). ${ }^{59}$

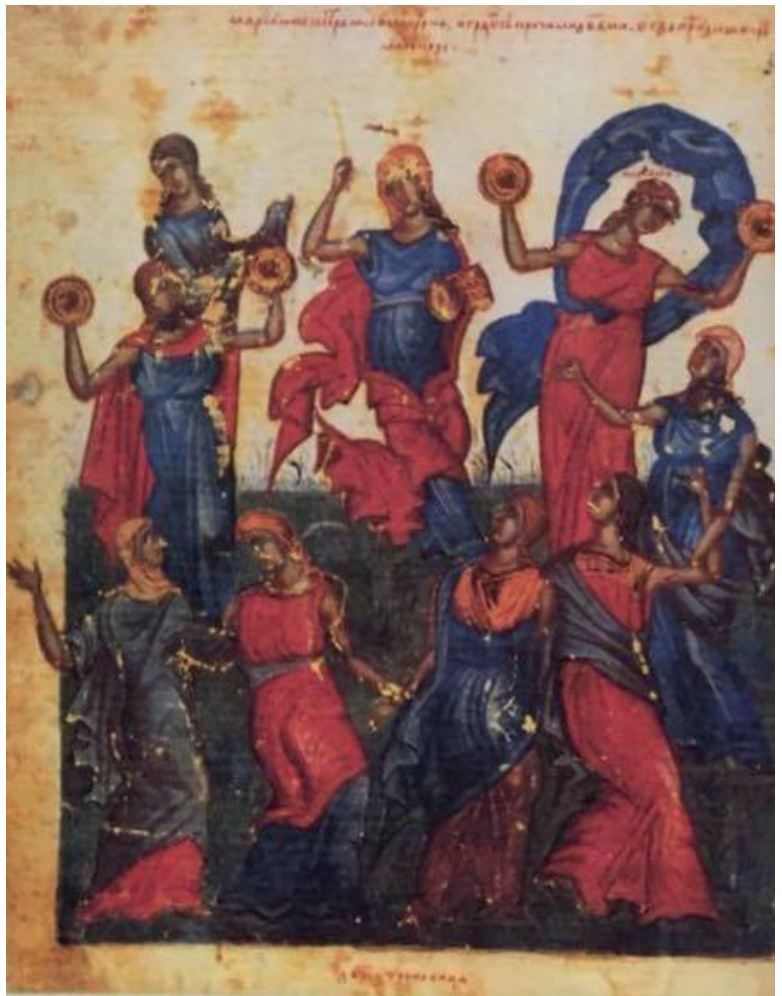

F. 11: Miryam'ın ve Etrafındaki Kadınların Dansı, El Yazması, XIV. yüzyılın ikinci yarıs1,

Kaynak: Moskova Ulusal Tarih Müzesi (State Historical Museum Moskov), Muz. 2752, fol. 249 r

Tool", Dedica Revista de Educação e Humanidades, 3 Granada, 2012, s. 153.

59 Bkz. Zvi, Friedhaber, Judith Brin, Ingber, Moshe, Silberschien, "The Dance with the Separating Kerchief”, Dance Research Journal, Vol. 17/18, Vol. 17, NO. 2 - Vol. 18, No. 1, Pub. by: Congress on Research in Dance, USA., 1985, s. 65-69; Maria, Parani, Reconstructing the Reality of Images: Byzantine Material Culture and Religious Iconography $11^{\text {th }}-15$ th Centuries, Leiden-Boston, 2003, s. 77. 
Geçmiş dönem izlerinin takip edildiği fakat aynı zamanda kendi dönemine kimlik kazandıracak özgün işlerin yapıldığı Bizans İmparatorluğu'nda, tasvir sanatı alanında uygulanan son dans biçimi, genellikle sarayda, imparator adına düzenlenen organizasyonlarda ya da "Burmalia" adı verilen festivallerde tatbik edilen "saximos ( $\left.\sum \dot{\alpha} \xi \xi \mu o \varsigma\right)$ " adı verilen danstır. ${ }^{60}$ Amaç ve kapsamı bilinen dansın fiilen uygulanma şekli ve bunun sanata yansıyış biçimi hakkında çok fazla bilgiye ulaşılamamıştır.

Bizans Dönemi’nde, bazen bir düğün alayının eşsiz coşkusunda (F. 12.), bazen kuralları kesin hükümlerle belirlenmiş resmi bir törenin ciddi atmosferinde (F. 13.), bazen iki minik çocuğun sevimliliğinde (F. 14), bazen de erk sahibi bir adamın sahip olduğu güce yansıyan ihtişamda (F. 15.) görüp incelediğimiz, olay-kişi-kostüm gibi belli unsurlar temelinde ilginç sanatsal özellikler var eden dans tasvirlerinin, dönem insanlarının günlük yaşam değerlerinin tahlil edilebilmesi için önemli ipuçları sunduğu görülmüştür. Sosyal yaşam dinamikleri içinde yer alan, uygulanış biçimleriyle kültür adı verilen birikimde kendince bir yer oluşturabilen dansın, Geç Antik Dönem'den Post-Bizans Dönemi’ne kadar süreklilik arz ederek değişik şekillerle karşımıza çıkması ve ortaya koymuş olduğu her bir detayla toplum hakkında belli yargılara varılmasını sağlayan kanıtlar sunması, bu durumun ispat niteliğini taşımıştır.

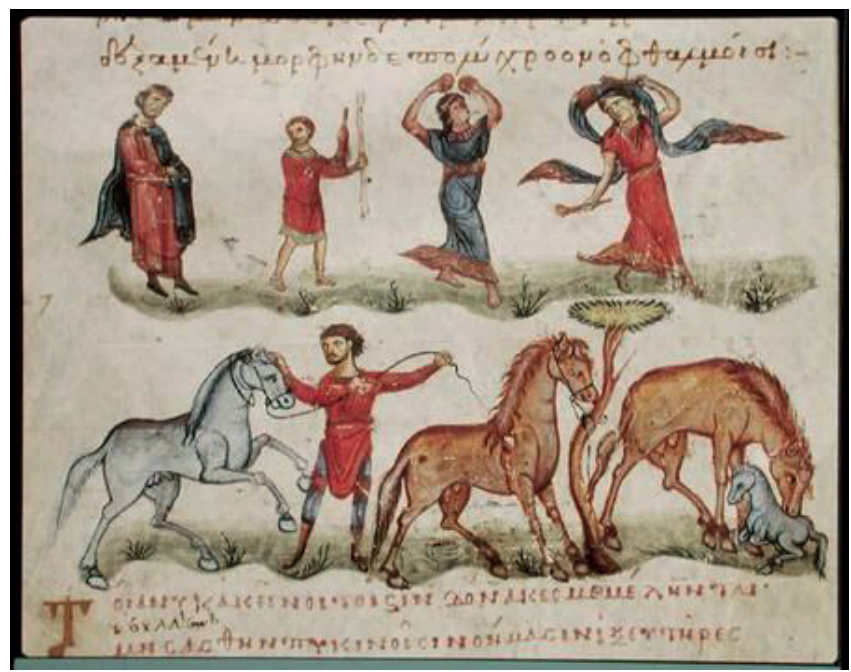

F. 12: Bir Düğün Sahnesi (Dans Edenler), El Yazması, XI. yüzyıl, Kaynak: Biblioteca Marcina, Marc. Gr. 479, fol, 12v

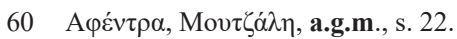




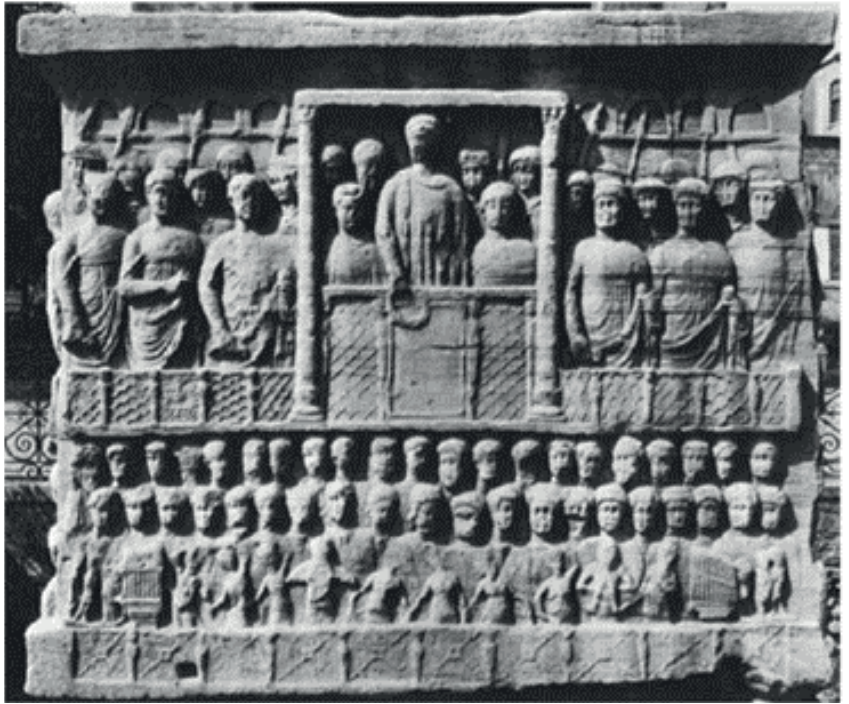

F. 13: Theodosius Obeliski, Hippodrom İstanbul, IV. yüzyıl, Güneydoğu Cephe, Kaynak: Weitzmann Kurt (1979), Age of Spirituality: Late Antique and Early Christian Art, Third to Seventh Century: Catalogue of the Exhibition at the Metropolitan Museum of Art, s. 108, fig. 37.

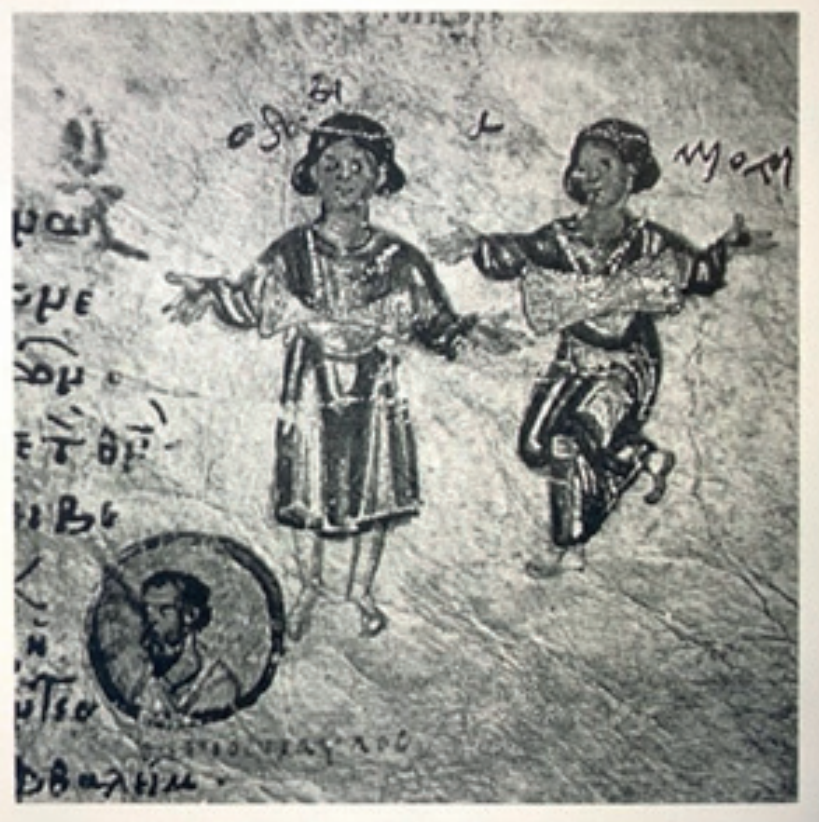

F. 14: Dans Eden Çocuklar, El Yazması, IX. yüzyıl,

Kaynak: Psalter, Cod. Athos Pantokrator 61, fol. 85 r, 9 


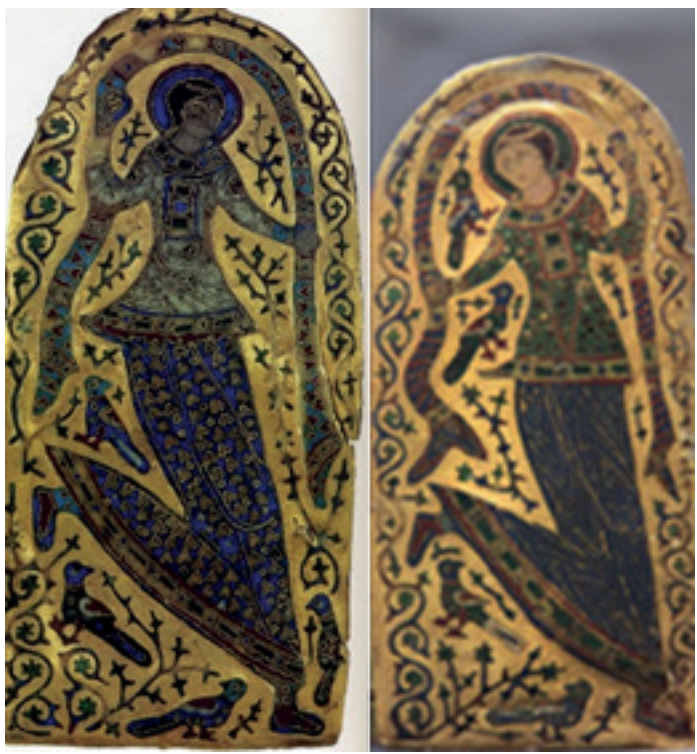

F. 15: IX. Konstantine Monomakhos'ın Tacı Üzerinde Tasvir Edilen İki Kadın Dansçı, XII. yüzyı1, Magyer Namzeti Müzesi (Museum), Budapeşte,

Kaynak: https://mnm.hu/hu/gyujtemenyek/archaeological-department/kozepkoriotvosgyujtemeny $(30.11 .2019)$

Bizans Dönemi'nde, insan ve onun yaşamına dair belli kriterlere ulaşılmasında önemli bir rol üstlenen dansın en güzel görsel temsillerine; sivil (bu şekliyle eğlence ve neşeye gönderme yapan bir form) ve dini olmak üzere bu iki alan kapsamında verilen eserler üzerinde yer verildiği görülmüştür. Kamuya açık meydanlarda ya da bireysel olarak evlerde bir festival ya da eğlence kapsamında düzenlenen şenliklerde tatbik edilen dansın; süs objeleri, takılar, tekstil parçaları ya da mimari plastik gibi örneklerini çoğaltabileceğimiz farklı gruplar üzerinde yer alan tasvirleri, sivil alanda verilen örnekleri temsil ederken ibadet maksadına hizmet eden bir biçimle kiliselerde ve burada bir öğretim mekanizması olarak kullanılan el yazmalarında işlenen dans tasvirleri ise dini alanda verilen görsel temsillerin en güzel örneklerini oluşturmuştur.

Bizans Dönemi'nde sosyal ve kültürel hayatta olduğu kadar sanat hayatında da nitelikli bir yer edinen dans temasının, sanatkârlar tarafından özellikle din temelli mekân ve eserlerde belli ikonografik konuların takibi göz önünde bulundurularak işlendiği bu anlamda tasvirlerin makul bir sıra var edilerek ele alındığı görülmüştür. Daha çok kilise ve el yazmalarında karşılaşılan "İsa'yla Alay Edilmesi”, "Salome 'nin Yedi Tül Dansı", “Miryam'in Dansı”, “Davut Peygamber'in Dansı”, “Musa Peygamber 'in Dansı”, inanca ve inançla gelecek olan huzura temsil sayılan "Dairesel Danslar" gibi temalar, bu durumu örneklemiştir. İbadet mekanlarında ya da inanılan sistemin ana malzemesi olarak kullanılan materyallerde, sanatkarlar tarafından tercih edilerek tasvirine yer verilen konularla kimi 
zaman kıssadan hisse alınacak değerler tartışılmış ( "Ísa 'yla Alay Edilmesi”, "Salome’nin Yedi Tül Dansı”) kimi zaman da inanılan sistem içerisinde, önder kabul edilen kişi ve kişilerin uyguladığı dans biçimleri anlatılarak ("Miryam'ın Dansı”, "Davut Peygamber'in Dansı”, "Musa Peygamber 'in Dansı”, “Dairesel Danslar”) din ve toplum yaşamı arasında bir uzlaşı ortamının var edilmesi sağlanmıştır. Örneğin; "Salome’nin Yedi Tül Dansı" ile kadın bedenine yüklenilen anlam Miryam ’n Dansı" nın getirmiş anlamla değișmiş; inanç unsuruyla yaratılan kısmi baskının ötelenmesi ve bunun bir kültür unsuru olarak kabul edilmesi olanaklı hale getirilmiştir. Düzenlenen "Dairesel Danslar" ile cennet temsili yaratılmaya çalışılmış, dansın ortaya çıkışında etken bir rol üstlenen ibadet unsuru vurgulanır hale getirilmiştir. İnsan ve toplum nazarında eğlence ve sefanın göstergesi olarak kabul gören dansın, yeri ve değeri değiştirilmeye çalışmış; ritmik bir beden anlayışı bir anda özgürleşen ruh kavramıyla tanıştırılmıştır.

Yaş, cinsiyet fark etmeksizin farklı niteliklere sahip pek çok kişi tarafından tatbik edilen bu şekliyle halk kitleleri tarafından haşir neşir olunan bir fiile dönüşen, dolayısıyla yaşayan bir gelenek haline gelen dans, sosyal ve kültürel hayat içerisindeki anlam ve misyonuyla sanat sahasında var ettiği yerde önem kazanmış, günümüze kadar gelen pek çok örnekle sevilmeye ve tanınmaya devam eden bir eylem haline dönüşmüştür.

Hakem Değerlendirmesi: Dış bağımsız.

Çıkar Çatışması: Yazar çıkar çatışması bildirmemiştir.

Finansal Destek: Yazar bu çalışma için finansal destek almadığını beyan etmiştir.

Peer-review: Externally peer-reviewed.

Conflict of Interest: The author has no conflict of interest to declare.

Grant Support: The author declared that this study has received no financial support.

\section{Kaynakça/References}

Bartlett, David L., Brown Taylor, Barbara, Feasting on the World Preaching the Revised Common Lectionary,

Year A, Volume 2 Lent Through Eastertide, Westminster John Knox Press, USA., 2010.

Brown, Peter Robert Lamont "Enjoying the Saints in Late Antiquity”, Early Medieval Europe Journal, Vol.

9, USA., 2000, s. 1-24.

Burkert, Walter, Greek Religion, Harvard University Press, USA., 1985.

Choniates, Nicetas, O City of Byzantium: Annals of Niketas Choniatēs, Trans. by. Harry J. Magoulias, Wayne State University Press, Michigan, 1984.

Clement of Alexandria, The Instructor (Paedagogus), Fathers of the Second Century: Hermes, Tatian, Athenagoras, Theophilus, and Clement of Alexandria (Entire), Trans. by. William Wilson Vol. II, Christian Literature Publishing Company, NewYork, 1885.

Danforth, Loring M. "The Rôle of Dance in the Ritual Therapy of the Anastenaria”, Byzantine and Modern Greek Studies, Cambridge University Press, 1979, s. 141-163.

Danforth, Loring M., "Power through Submission in the Anastenaria", Journal of Modern Greek Studies, Vol. 1, No. 1, Johns Hopkins University Press, USA., 1983, s. 203-223. 
Dierkes-Thrun, Petra, Salome's Modernity: Oscar Wilde and the Aesthetics of Transgression, University of Michigan Press, USA, 2014.

Dodd, Erica Cruikshank- Kent, John, Byzantine Silver Stamps, Washington, 1961.

Evans, Helen C.,-RATLIFF, Brandie, Byzantium and Islam : Age of Transition, 7th-9th Century, Metropolitan Museum of Art, Yale University Press, New York, 2012.

Friedhaber, Zvi, Ingber, Judith Brin, , Silberschien, Moshe, “The Dance with the Separating Kerchief”, Dance Research Journal, Vol. 17/18, Vol. 17, NO. 2 - Vol. 18, No. 1, Pub. by: Congress on Research in Dance, USA., 1985, s. 65-69.

Gaston, Anne-Marie (Anjali)- Gaston, Tony, "Dance as a Way of Being Religious", The Oxford Handbook of Religion and the Arts, Ed. By. Frank Burch Brown, Oxford University Press, UK., 2014, s. 2-24.

Graf, Fritz, Apollo, Routledge, UK., 2008.

Grossman, D., "When the Daughter Came in and Danced: Revisiting Salome's Dance in Medieval and Early Modern Iconology", Interruptions and Transitions: Essays on the Senses in Medieval and Early Modern Visual Culture, Baert, Barbara, Brill Press, USA, 2019, s. 169 - 220.

Hoerburger, Felix, "Once Again: On the Concept of Folk Dance”, Journal of The International Folk Music Council, Vol. 20, USA, 1968, s. 30-32.

James, Elizabeth, Women, Men and Eunuchs: Gender in Byzantium, Routledge, London, 2013.

Jeanne Cohen, Selma, Next Week, Swan Lake: Reflections on Dance and Dances, Wesleyan University Press, USA., 2001.

Keiko, Kono, "Notes on the Dancers in the Mocking of Christ at Staro Nagoričino", Deltion of the Christian Archaeological Society, 27.4, USA, 2006, s. 159-68.

Kitzinger, Ernst, Byzantine Art in the Making: Main Lines of Stylistic Development in Mediterranean Art, 3rd-7th Century, Harvard Univeristy Press, USA., 1977.

Koder, Johannes, “Kordax Und Methe: Lasterhaftes Treiben In Byzantinischer Zeit”, Zbornik radova Vizantoloskog Instituta, 50/2, Serbia, 2013, s. 947-958.

Kultermann, Udo, "The "Dance of the Seven Veils". Salome and Erotic Culture Around 1900", Artibus et Historiae, Vol. 27, No. 53, Poland, 2006, s. 187-215.

Langford, Rachael, Depicting Desire: Gender, Sexuality, and the Family in Nineteenth Century Europe: Literary and Artistic Perspectives, Peter Lang, Oxford, 2005.

Larson, Jennifer, "Handmaidens of Artemis?”, The Classical Journal, Vol. 92, No. 3, Pub. by. The Classical Association of the Middle West and South, Inc. (CAMWS), USA., 1997, s. 249-257.

Ley, Graham, The Theatricality of Greek Tragedy: Playing Space and Chorus, University of Chicago Press, USA., 2010.

Littlewood, Anthony Robert, Michaelis Pselli Oratoria Minora Leipzig, 1985.

Lohse-Claus, Elli, Tanz in der Kunst, Zentralantiquariat Leipzig GmbH, Leipzig, Germany, 1964.

Lucian, "Of Pantomimes" In the Works of Lucian of Samosata, Trans. by. FOWLER, H. W.-FOWLER, F G., Clarendon Press, UK., 1905.

Lundskow, George, The Sociology of Religion: A Substantive and Transdisciplinary Approach, Pine Forge Press, UK., 2008.

Moran, Neil K., Singers in Late Byzantine and Slavonic Painting, Brill Press, Leiden-Boston, 1986.

Naerebout, Gerard F., Attractive Performances: Ancient Greek Dance : Three Preliminary Studies, J.C. 
Gieben, Amsterdam, 1997.

Neginsky, Rosina, Salome: The Image of a Woman Who Never Was; Salome, Cambridge Scholars Publishing, USA., 2014.

Nibley, Hugh, “The Early Christian Prayer Circle”, Brigham Young University Studies Quarterly, Vol. 19/1, UK., 1979, s. 1-37.

Parani, Maria, Reconstructing the Reality of Images: Byzantine Material Culture and Religious Iconography 11Th-15th Centuries, Leiden-Boston, 2003.

Plutarch, Plutarch's Morals, Vol. 4, Ed. by. William W Goodwin, Little, Brown and Company, Boston, 1874.

Polen, Nehemia Polen, “Miryam's Dance: Radical Egalitarianism in Hasidic Thought”, Judaism, Vol. 12, No.

1, Oxford University Press, UK. 1992, s. 1-21.

Roberts, Helene E., Encyclopedia of Comparative Iconography: Themes Depicted in Works of Art, Routledge, UK., 2013.

Speck, Paul, Understanding Byzantium: Studies in Byzantine Historical Sources, Ed. by. Takacs Sarolta, Routledge, USA., 2003.

Steppan, Thomas, “Tanzdarstellungen der mittel- und spätbyzantinischen Kunst”, Cahiers Archéologiques 45, Paris, 1997, s. 141-168.

Stiga, Kalliopi, Kopsalidou, Evangelia, "Music and Traditions of Thrace (Greece): A Trans-Cultural Teaching Tool”, Dedica Revista de Educação e Humanidades, 3 Granada, 2012, s. 145-164.

Van Der Leeuw, Gerardus, Sacred and Profane Beauty: The Holy in Art, New York, 1963.

Vaughan, Laura, Suburban Urbanities: Suburbs and the Life of the High Street, UCL Press, London, 2015. Weitzmann, Kurt (1979), Age of Spirituality: Late Antique and Early Christian Art, Third to Seventh Century: Catalogue of the Exhibition at the Metropolitan Museum of Art, November 19, 1977, Metropolitan Museum of Art, New York.

Yarber, Angela M., Dance in Scripture: How Biblical Dancers Can Revolutionize Worship Today, Wipf and Stock Publishers, Eugene-Oregon, 2013.

Z. Pevny, Olenka, The Glory of Byzantium; Perceptions of Byzantium and Its Neighbors; Metropolitan Museum of Art, New York, 2000.

\section{Yunanca Kaynakça}

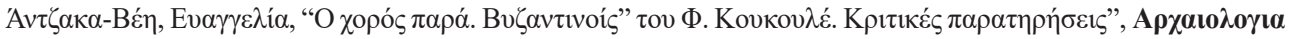

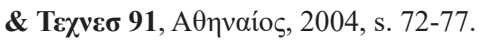

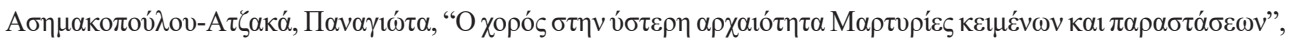

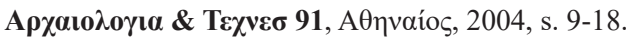

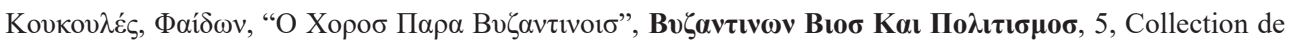
l'Institut Français d' Athènes, 1938, s. 217-257.

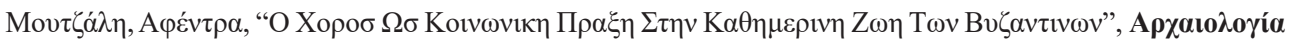

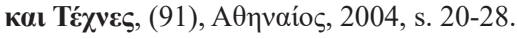

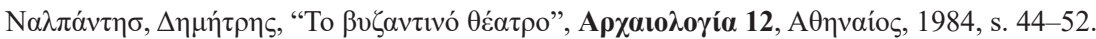

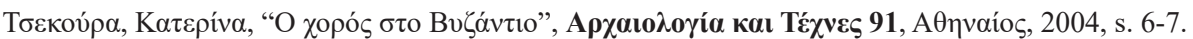




\section{El Yazmaları}

Biblioteca ApostolicaVaticana.

Paris, Bibliothèque Nationale.

Psalter, Cod. Athos Pantokrator 61.

Biblioteca Marcina, Marc.

\section{Web Kaynakları}

http://lucianofsamosata.info/wiki/doku.php?id=home:texts_and_library:dialogues:of-pantomime (13.12.2019). https://collections.vam.ac.uk/item/O70463/veroli-casket-casket-unknown/ (30.11.2019). http://diglib.library.vanderbilt.edu/act-imagelink.pl?RC=55470 (27.01.2020). https://gallica.bnf.fr/ark:/12148/btv1b84522082/f542.highres (27.01.2020). http://www.hellenicaworld.com/Byzantium/LX/en/DanceOfMiryam2.html(30.11.2019). http://www.rebetikoseminar.com/wp-content/uploads/2015/12/praktika_3_2011.pdf(29.01.2020). https://research.britishmuseum.org/research/collection_online/collection_object_details. aspx?objectId=808634\&page=1\&partId=1\&searchText=great\%20plate\%20of\%20bacchus (20.01.2020). https://art.thewalters.org/detail/34927/jewelry-box-with-dancers-and-faun/ (27.01.2020).

https://dd5a2c7c-a-62cb3a1a-s-sites.googlegroups.com/site/byzantinedance/home/page-2/14th-century-ad/ P6271B.JPG?attachauth=ANoY7cps_b0LsI_VrrqNtB9NPPi9dpG083sWSGsLKhQV2d7zrM7Otg5almt BiEOV-wMG8h0z0kxCTT0VQAbBWetljJjvq1JX3SmkqmoLd9Iuf9-K_esyZyLTWoxNWLUiTUV1WT WyzI9in612rlLwnPnG-jfn4E3jvvieGiCeuCY1op_m6LgRP9H8sbxoHg3iBQD-HnZGKUdfdBMZ2ZXF0 e2i0CEfMKBKdx04pRqNypuKG84E4kBdXT-d2IUF3QRuSR8Z-4-tU678\&attredirects=0 (27.01.2020). https://athosweblog.com/2017/05/04/1910-koutloumousiou-monastery-part-3/ (30.01.2020). https://mnm.hu/hu/gyujtemenyek/archaeological-department/kozepkori-otvosgyujtemeny (30.11.2019). 
